\title{
Comparative proteomics of three Chinese potato cultivars to improve understanding of potato molecular response to late blight disease
}

Chunfang Xiao ${ }^{1,2,3}$, Mengling Huang ${ }^{1}$, Jianhua Gao ${ }^{2,3}$, Zhen Wang ${ }^{2,3}$, Denghong Zhang ${ }^{2,3}$, Yuanxue Zhang ${ }^{2,3}$, Lei $\mathrm{Yan}^{2,3}$, Xiao $\mathrm{Yu}^{1}$, Bo Li ${ }^{1 *}$ and Yanfen Shen ${ }^{2,3^{*}}$

\begin{abstract}
Background: Late blight disease (LBD) caused by the pathogen Phytophthora infestans (PI), is the most devastating disease limiting potato (Solanum tuberosum) production globally. Currently, this disease pathogen is re-emerging and appearing in new areas at a very high intensity. A better understanding of the natural defense mechanisms against PI in different potato cultivars especially at the protein level is still lacking. Therefore, to elucidate potato proteome response to $\mathrm{Pl}$, we investigated changes in the proteome and leaf morphology of three potato cultivars, namely; Favorita (FA), Mira (MA), and E-malingshu N0.14 (E14) infected with PI by using the iTRAQ-based quantitative proteomics analysis.

Results: A total of 3306 proteins were found in the three potato genotypes, and 2044 proteins were quantified. Cluster analysis revealed MA and E14 clustered together separately from FA. The protein profile and related functions revealed that the cultivars shared a typical hypersensitive response to PI, including induction of elicitors, oxidative burst, and suppression of photosynthesis in the potato leaves. Meanwhile, MA and E14 deployed additional specific response mechanism different from FA, involving high induction of protease inhibitors, serine/ threonine kinases, terpenoid, hormone signaling, and transport, which contributed to MA tolerance of LBD. Furthermore, inductions of pathogenesis-related proteins, LRR receptor-like kinases, mitogen-activated protein kinase, WRKY transcription factors, jasmonic acid, and phenolic compounds mediate E14 resistance against LBD. These proteins were confirmed at the transcription level by a quantitative polymerase chain reaction and at the translation level by western-blot.

(Continued on next page)
\end{abstract}

\footnotetext{
*Correspondence: boli@mail.hzau.edu.cn; shenyanfen1976@126.com

'State Key Laboratory of Agricultural Microbiology and Hubei Key Laboratory of Plant Pathology, College of Plant Science and Technology, Huazhong Agricultural University, Wuhan 430070, Hubei, China

${ }^{2}$ Southern Potato Research Center of China, Enshi 445000, Hubei, China

Full list of author information is available at the end of the article
}

C C The Author(s). 2020 Open Access This article is licensed under a Creative Commons Attribution 4.0 International License, which permits use, sharing, adaptation, distribution and reproduction in any medium or format, as long as you give appropriate credit to the original author(s) and the source, provide a link to the Creative Commons licence, and indicate if changes were made. The images or other third party material in this article are included in the article's Creative Commons licence, unless indicated otherwise in a credit line to the material. If material is not included in the article's Creative Commons licence and your intended use is not permitted by statutory regulation or exceeds the permitted use, you will need to obtain permission directly from the copyright holder. To view a copy of this licence, visit http://creativecommons.org/licenses/by/4.0/ The Creative Commons Public Domain Dedication waiver (http://creativecommons.org/publicdomain/zero/1.0/) applies to the data made available in this article, unless otherwise stated in a credit line to the data. 


\begin{abstract}
(Continued from previous page)
Conclusions: We found several proteins that were differentially abundant among the cultivars, that includes common and cultivar specific proteins which highlighted similarities and significant differences between FA, MA, and E14 in terms of their defense response to PI. Here the specific accumulation of mitogen-activated protein kinase, Serine/threonine kinases, WRKY transcription played a positive role in E14 immunity against PI. The candidate proteins identified reported in this study will form the basis of future studies and may improve our understanding of the molecular mechanisms of late blight disease resistance in potato.
\end{abstract}

Keywords: Comparative proteomics, Potato cultivars, Phytophthora infestans, Late blight disease, Hypersensitive response, Susceptible, Tolerance, Resistant

\section{Background}

Phytophthora infestans (PI), the causative agent of late blight disease (LBD) of the family Solanaceae, is reemerging and appearing in new areas at very high intensity [1]. When control fails, LBD epidemy damage foliage and tubers, which can lead to total crop failure, especially in potato (Solanum tuberosum) [1, 2]. LBD was responsible for potato famine in Europe in the nineteenth century which led to several deaths [3], and to date, LBD remains a global food security threat with an estimated cost in billions of dollars in control measures and crop losses $[4,5]$. The predicted rise in global temperature could upsurge LBD incidence, particularly in humid areas [6], and may lead to the emergence of new aggressive PI strains, and worsen the challenges already facing potato industries around the world.

Host genetic resistance is the most sustainable mechanism to combat PI, and some members of the Solanaceae family are known to maintain a range of locus diversity for LBD resistance [7]. However, evidence of partial or complete breakdown of some resistance (R) loci has emerged $[8,9]$, which underscores the need to explore additional sources of LBD resistance within potato germplasm to understand the molecular mechanism underpinnings different types of potato resistance to LBD. Such information will be useful for developing breeding strategies for combatting LBD.

Generally, host defense and immunity against pathogenic attack initiate with the recognition of highly conserved pathogen-associated molecular patterns (PAMPs) by the cell surface pattern-recognition receptors (PRRs), which trigger host immunity (PAMP-triggered immunity-PTI) [10]. However, our knowledge of PRRs in potato is limited. PI colonizes host cells by suppressing basal immunity with an array of effector proteins, leading to effector-triggered susceptibility (ETS) $[4,5,11]$. Through evolution, host plants have evolved dominant $\mathrm{R}$ genes to counter ETS $[5,12]$. Most $\mathrm{R}$ genes code for proteins with $\mathrm{N}$-terminal nucleotide-binding site (NBS) and C-terminal leucine-rich repeat (LRR) that recognize pathogen effectors, and establish effectortriggered immunity (ETI) $[12,13]$. However, to date, a comprehensive understanding of potato proteins involved in ETI and associated biological processes and molecular mechanisms that result in hypersensitiveresponse (HR-phenotype)-related programmed cell death (PCD) and overall immunity against PI is still lacking [14]. Through transcriptomic studies $[12,15,16]$ the transcriptional response of potato to PI effectors are well understood, less understood, however, is the PI effectorinduced changes in potato at the proteome level. This has remained a challenge because (1) mRNA does not always provide information on protein abundance across disease conditions [17]. (2). Protein synthesis can be further regulated at the translational and post-translational level, a phenomenon common in plant responses to stress, (3) Proteins ultimately control biological processes. Therefore, the proteomic landscape provides a holistic view of potato response to PI invasion.

Label-free and labeled quantitative proteomics has become a favorite tool to quantify global changes in protein abundance during plant and pathogen interactions, and to identify associated biological and molecular processes including candidate proteins underlying susceptible, tolerance, or resistance against pathogens $[18,19]$. For example, methods like isobaric tags for relative and absolute quantification (iTRAQ) and tandem mass tags (TMT) are routinely used by different platforms because they are compatible with samples from multiple sources [20]. Its potential has been demonstrated in many crop species, including potato response to PI [4], potato cell wall proteins associated with PI pathogenicity [21], and protein profiling of potato leaf tissues [19].

This study reports the response of three Chinese potato varieties: Favorita (FA), Mira (MA), and Emalingshu N0.14 (E14) during potato foliage-PI interactions and revealed potato proteins, biological and metabolic functions target by PI using a combination of ITRAQ-based quantitative proteomics, western blot analysis, and quantitative real-time polymerase chain reaction (qPCR). We found that after infection of potato leaves with PI, the FA plants exhibited a gross morphology of leaves usually observed in cultivars susceptible to PI. MA exhibited similar to the cultivars tolerant to 
PI, while the phenotype of E14 was immune to $P$. infestans.

\section{Results}

Morphological response of different potato cultivars subjected to $P$. infestans infection (PI)

The Favorita (FA), Mira (MA), and E-malingshu NO. 14 (E14) cultivars were chosen for this study based on their frequently use as elite parents in potato breeding programmes across China [22, 23]. To examine the morphological responses of each potato cultivars to LBD pathogen PI, we scored potato leaves for disease severity at $5 \mathrm{dpi}$ based on hypersensitive reaction (HR) or expanding lesion size [24]. Figure 1a shows the leaf phenotype of FA, MA, and E14 infected and control plants. The difference in disease severity indicates that FA-Phy had a higher degree of wilting and disease lesions compared to FA control, MA-Phy, and E14-Phy (Fig. 1b). In contrast, leaves of MA-Phy plants with PI had fewer signs of HR lesions compared to FA-Phy plants, but the severity of HR lesions was significantly different compared to MA control (Fig. 1b). The E14-Phy plants had no visible disease symptoms, and the leave morphology was similar to controls plants (Fig. 1a and b). These results indicate that FA is susceptible to PI, MA is tolerant to PI, and E14 is resistant to PI.
iTRAQ analysis and profile of proteins altered by PI in FAPhy, MA-Phy, and E14-Phy

To reveal the molecular response of potato to PI infection at the protein level; we conducted iTRAQ-based proteomics experiments with three potato cultivars FA, MA, and E14 plants infected with PI and controls. We identified a total of 10,689 high-quality, unique peptides corresponding to 3306 proteins, and following the criteria described in the 'Materials and methods section,' we quantified 2044 proteins (Additional file 1: Fig. S1, Additional file 2: Table S1, and Additional file 3: Table S2 contains the complete list of identified peptides and proteins, and differentially abundant proteins (DAP) respectively, $p<0.05, \mathrm{FC}>1.2$, Fig. 2a). Furthermore, Pearson correlation analysis was used to assess the reproducibility of our iTRAQ-based proteomics experiments. The results show a high correlation among the replicates of each sample (Additional file 4: Fig. S2).

The pairwise comparison of the quantified proteins (infected vs. control plants), showed that 855 proteins were differentially abundant in the FA-Phy vs. FA. Out of which 498 proteins were up-regulated, and 357 proteins were down-regulated (Fig. 2b). In MA-Phy vs. MA, 441 proteins showed significant changes in their abundance, of which 227 were up-regulated, and 214 were down-regulated (Fig. 2c). Additionally, the E14-Phy vs. E14 had 748 DAPs, of which 518 were up-regulated, and 230 were down-regulated (Fig. 2d).

A

B
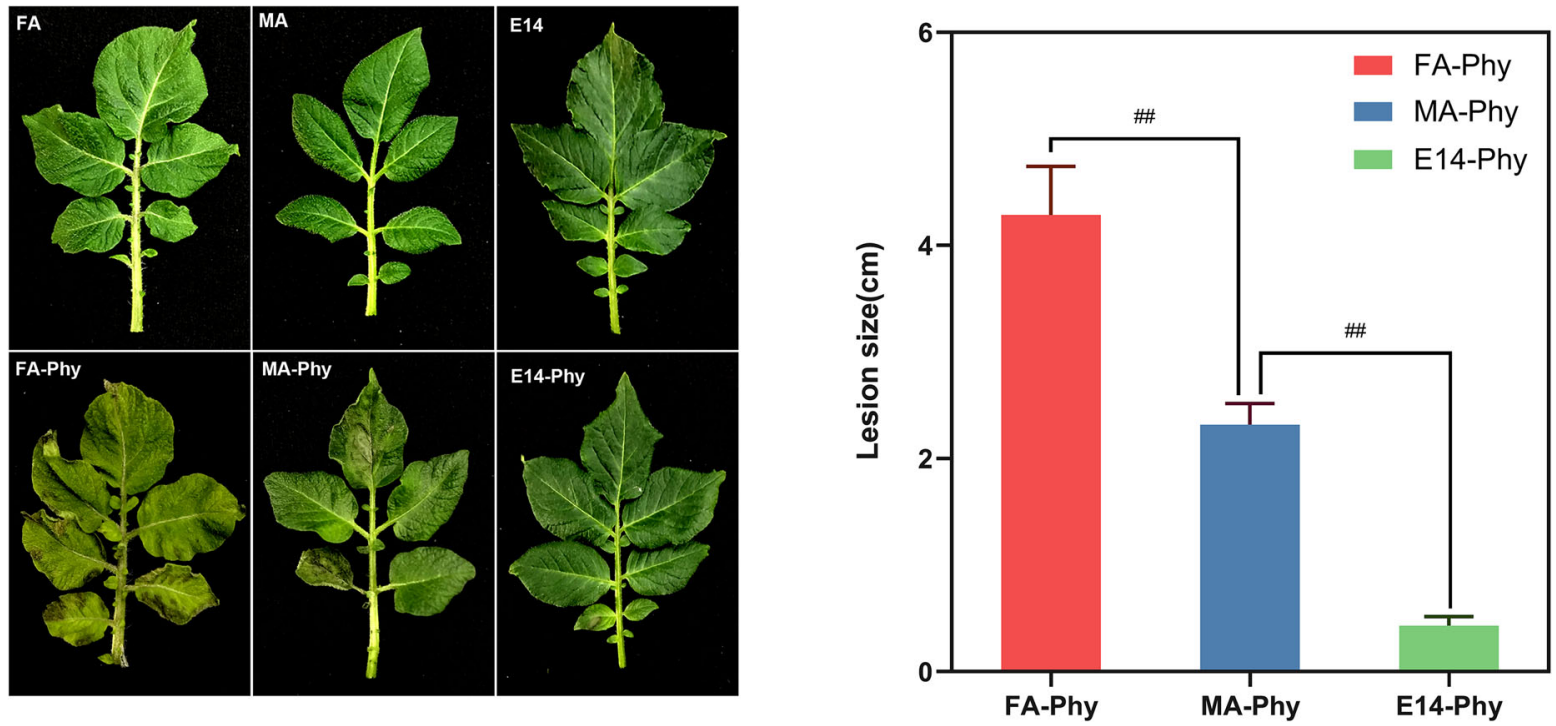

Fig. 1 Morphological analysis of the effect of PI treatment on FA, MA and E14, and control plants. A. Morphological observation of leaves of control plants and FA-Phy, MA-Phy and E14-Phy five days after PI inoculation. B. Statistical analysis of leaf lesion diameter of FA-Phy, MA-Phy and E14-Phy 5 days after inoculation. Three replicates were used for each treatment in these tests. Bars represent the standard deviation of three replicates. Statistical significance was analyzed using Student's t-test. The asterisk indicates the significant difference $\left({ }^{*} p<0.05\right)$ 

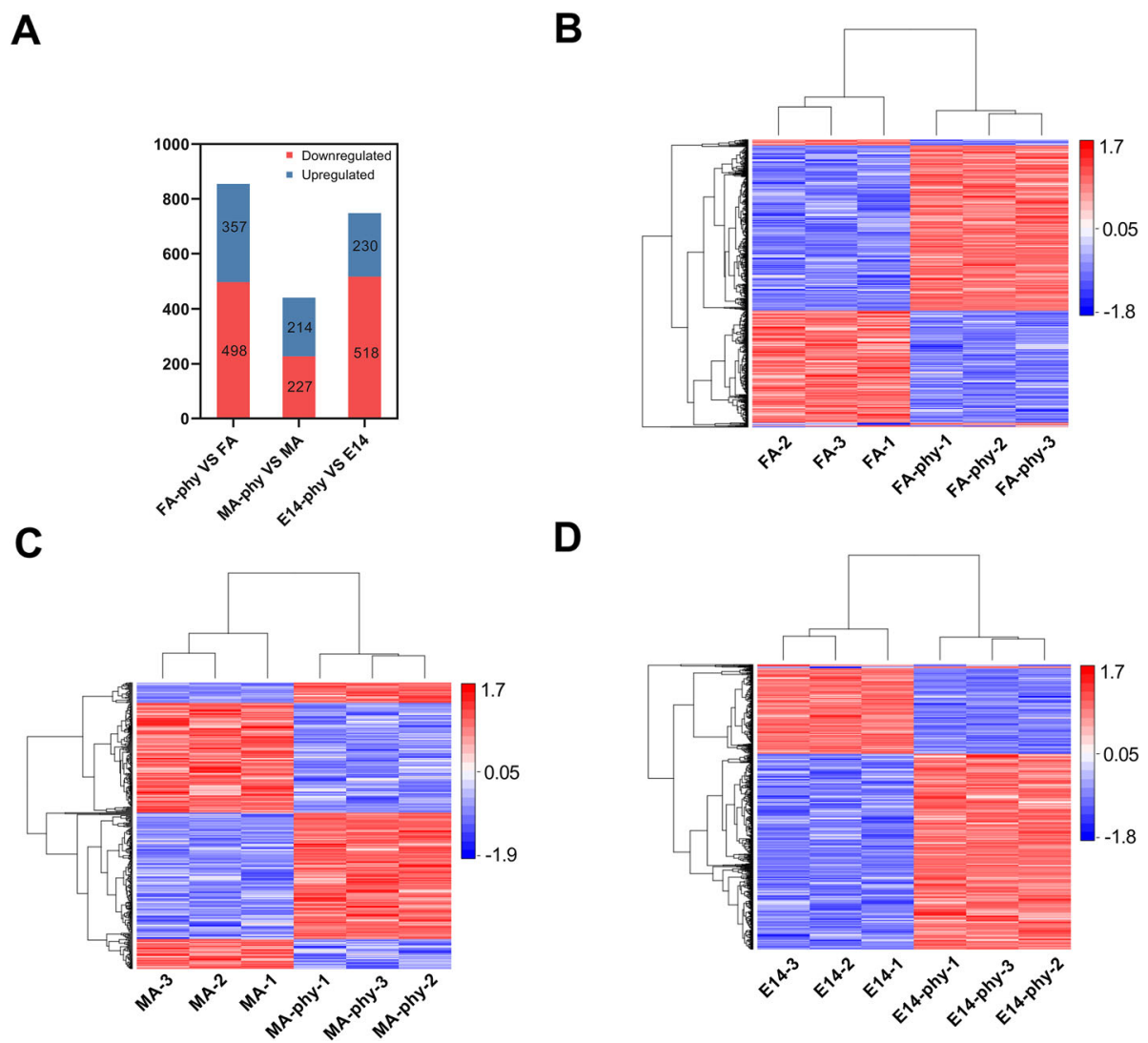

Fig. 2 Number of DAPs and their profile between PI treated plants and control. a Bar chart showing number of up-regulated and downregulated proteins in each pairwise comparison of FA-Phy vs. FA, MA-Phy vs. MA and E14-Phy vs. E14. Light blue color indicates down-regulated proteins and navy-blue color indicates up-regulated proteins. $\mathbf{b}, \mathbf{c}$, $\mathbf{d}$ Heat map showing abundance profile of proteins in FA-Phy vs. FA, MA-Phy vs. MA and E14-Phy vs. E14 comparison. Proteins with high abundance (red); proteins with low abundance (blue)

Cluster analysis of all DAPs showed that proteins of E14-Phy and MA-Phy clustered together separate from FA-Phy (Fig. 3a), suggesting that E14-Phy and MA-Phy have a similar response to PI infection different from FA-Phy. Potato proteins commonly or specifically targeted by PI were identified by overlapping of DAPs in FA-Phy, MA-Phy, and E14-Phy respectively (Fig. 3b). For example, 122 DAPs were shared by the three cultivars, of these, 83 proteins were simultaneously upregulated, and 24 proteins were consistently downregulated. Whereas 15 DAPs were dynamically regulated (either up-or-down-regulated in the three cultivars at the same time) in FA-Phy, MA-Phy, and E14-Phy respectively, (Additional file 5: Table S3). In addition to 247 DAPs shared between FA-Phy and E14-Phy, 98 DAPs common to FA-Phy and MA-Phy, and 80 DAPs are shared between MA-Phy and E14-Phy. In contrast, we identified, 338 DAPs exclusively abundant in FA-Phy, of these 235 proteins were up-regulated and 153 DAPs were down-regulated. The MA-Phy, had 141 uniquely abundant DAPs, out of which 58 proteins were upregulated and 83 proteins were down-regulated, and 299
DAPs were exclusively abundant in the E14-Phy, of which 201 proteins were up-regulated, and 98 were downregulated. Together these results highlight similarities and differences in regulation of protein abundance among the potato cultivars when challenged with PI.

\section{Gene ontology, enrichment, and pathway analyses} GO terms classification ("biological process," "molecular function" and "cellular component," categories) was used to gain information on the biological meaning of differentially abundant proteins (Fig. 4). The results showed that FA-Phy, MA-Phy, and E14-Phy have a similar distribution of GO terms. For example, in FA-Phy, 21 biological processes, 11 molecular functions, and 14 cellular components were altered by PI (Fig. 4a). MA-Phy had 20 biological processes, 15 cellular components, and 8 molecular functions categories (Fig. 4b), and E14-Phy had 20 biological processes, 15 for cellular component, and 11 for molecular functions (Fig. 4). Generally, about $70 \%$ of DAPs in the biological process was related to "metabolic process," and more than 54\% of the DAPs related to "cellular process" in each of the cultivar. 


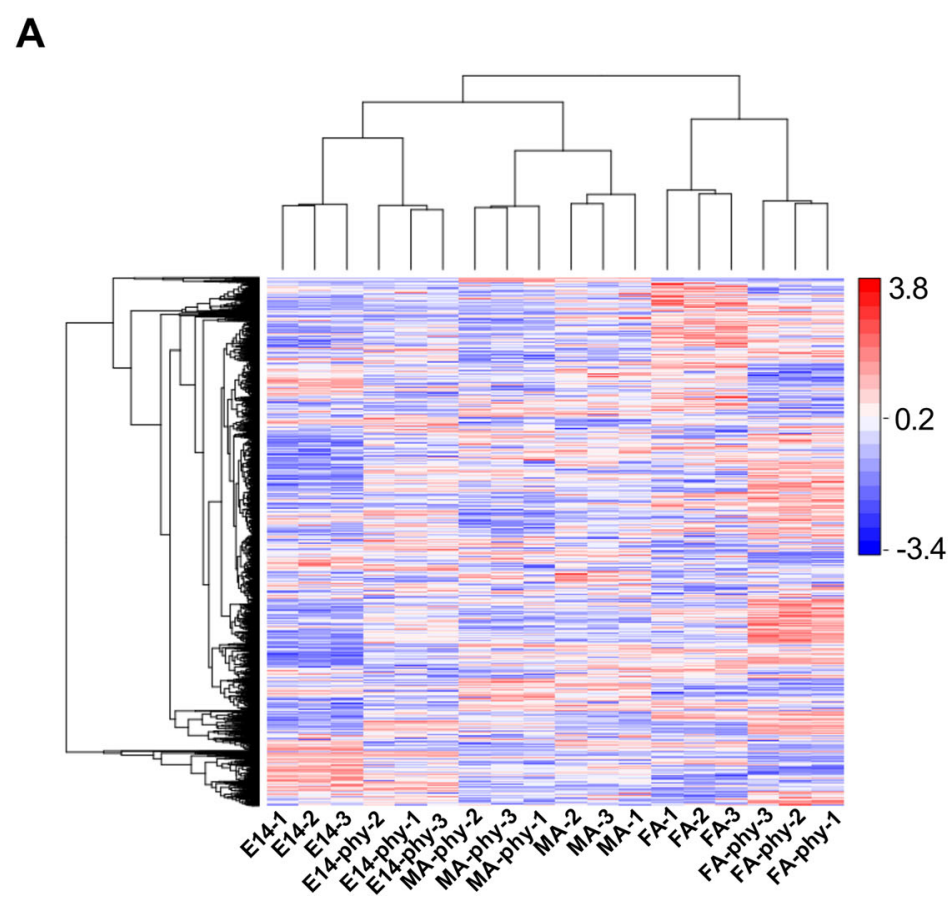

B

Fig. 3 Hierarchical clustering and overlapping proteins. a Cluster analysis of differential abundant proteins in FA-Phy vs. FA, MA-Phy vs. MA and E14-Phy vs. E14. Up-regulated proteins (red); down-regulated proteins (blue). b Venn diagram representing common and unique differential abundant proteins between FA-Phy vs. FA, MA-Phy vs. MA and E14-Phy vs. E14 comparisons

Similarly, "catalytic," and "binding" activity was the predominant molecular function shared by the three cultivars. And "cell," "organelles," "cellular membrane," and "macromolecular complex", were the dominant cellular component among the cultivars.

GO enrichment tests revealed over-represented biological process categories in FA-Phy, MA-Phy, and E14Phy respectively (Additional file 6: Fig. S3). For example, we found in FA-Phy, significant enrichment of positively regulated biological process categories that include "detoxification," "stimulus-response," "metabolic process," "single-organism process," and "cellular component organization or biogenesis." (Additional file 6: Fig. S3a). In contrast, the "immune system process" and "negative regulation of biological process" were negatively enriched (Additional file 6: Fig. S3b).

Similar to FA-Phy, we found "detoxification" and "stimulus-response" to be positively enriched in MA-Phy (Additional file 6: Fig. S3c-e). Nevertheless, we also noticed specific enrichment of "negative regulation of the biological process," "negative regulation of macromolecule metabolic process," and "negative regulation of the cellular metabolic process" in MA-Phy. And proteins that fell within these categories have functions associated with "peptidase/endopeptidase inhibitors, and endopeptidase enzyme regulators" (Additional file 6: Fig. S3c). Opposite to negative enrichment of "cellular process" and "developmental process" (Additional file 6: Fig. S3d).
Whereas in the E14-Phy, "defense response," "detoxification," immune response, and "negative regulation of the biological process" categories showed significant enrichment (Additional file 6: Fig. S3e). In contrast to negative enrichment of "cellular process" and "developmental process.

Among the cultivars, the KEGG pathway enrichment analysis further revealed common or specific pathways altered by PI (Fig. 5). For example, "valine, leucine and isoleucine degradation," "spliceosome," and "protein processing in the endoplasmic reticulum" were commonly enriched and positively induced in the three cultivars after PI infection." While "photosynthesis" and "porphyrin and chlorophyll metabolism" are consistently repressed (Additional file 7: Table S4). Alpha-Linolenic and linoleic" and "glutathione metabolism" were specifically enriched and positively induced in MA-Phy and E14-Phy but not FA-Phy. Previous reports suggest that $\alpha$-linolenic acid or linoleic acid are substrates for LOX and converted into hydroperoxy polyunsaturated fatty acids, which are substrates for many pathways involved in developmental processes and defense including jasmonic acid and salicylic acid, both of which are associated with HR-induced PCD [25]. Also, glutathione metabolism has been linked to the detoxification process and protection against oxidative stress [26]. Additionally, "plant-pathogen interaction pathway," "phenylpropanoid biosynthesis," and "biosynthesis of secondary metabolite" 


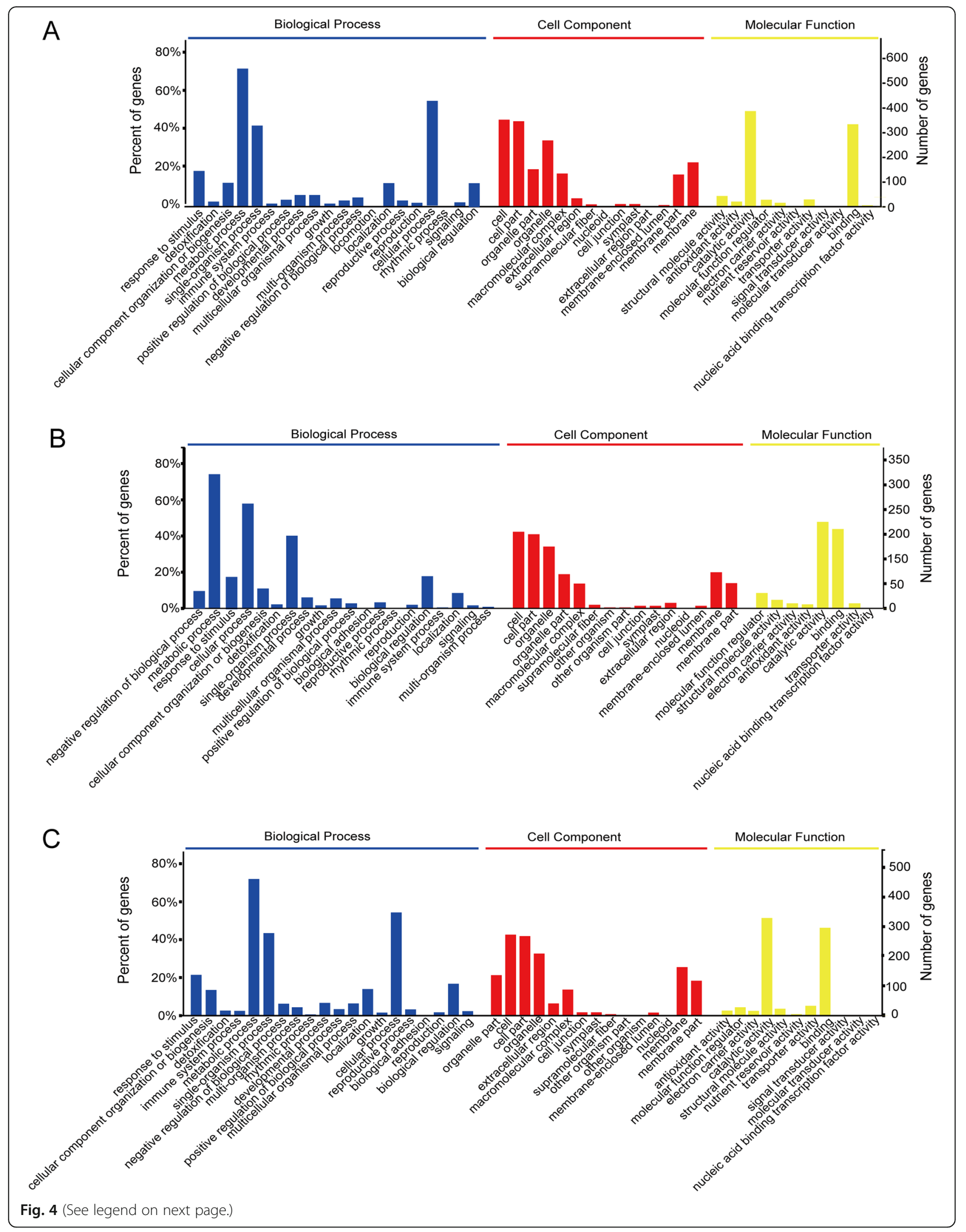


(See figure on previous page.)

Fig. 4 Gene ontology classification of differential abundant proteins identified in FA-Phy vs. FA, MA-Phy vs. MA, and E14-Phy vs. E14 comparison. The results are summarized in terms of three functional: cellular component, molecular function, and biological process. The blue bar represents biological process categories, the red bar represents $\mathrm{GO}$ terms for cellular component, and the yellow bar represents biological process categories to molecular function categories

pathways were uniquely enriched in E14-Phy infected plants but not MA-Phy and FA-Phy respectively.

The KEGG results suggest that up-regulation of LOX, glutathione metabolism, and plant-pathogen interaction, and phenylpropanoid biosynthetic pathways specific to MA-Phy and E14-Phy respectively might contribute to their phenotype after PI infection.

\section{Protein-protein interaction in the FA-Phy and E14-Phy}

To uncover the various functional aspects of potato PI interaction, we analyzed the protein-protein interaction
(PPI) that occurred in FA-PI and E14-PI using STRING (http://string-db.org). The PPI network for FA-PI (Fig. 6a) revealed a strong interaction between different protein classes, i.e., photosynthesis, electron transport, translation, ribosome biogenesis, and RNA metabolic process which showed maximum interactions. In opposite, we found very strong interaction among proteins that are involved in defense response, stimulus, protein folding, cellular amino acid metabolic process, biosynthesis of aromatic compounds, and cellular transport in the E14-PI PPI-network (Fig. 6b).

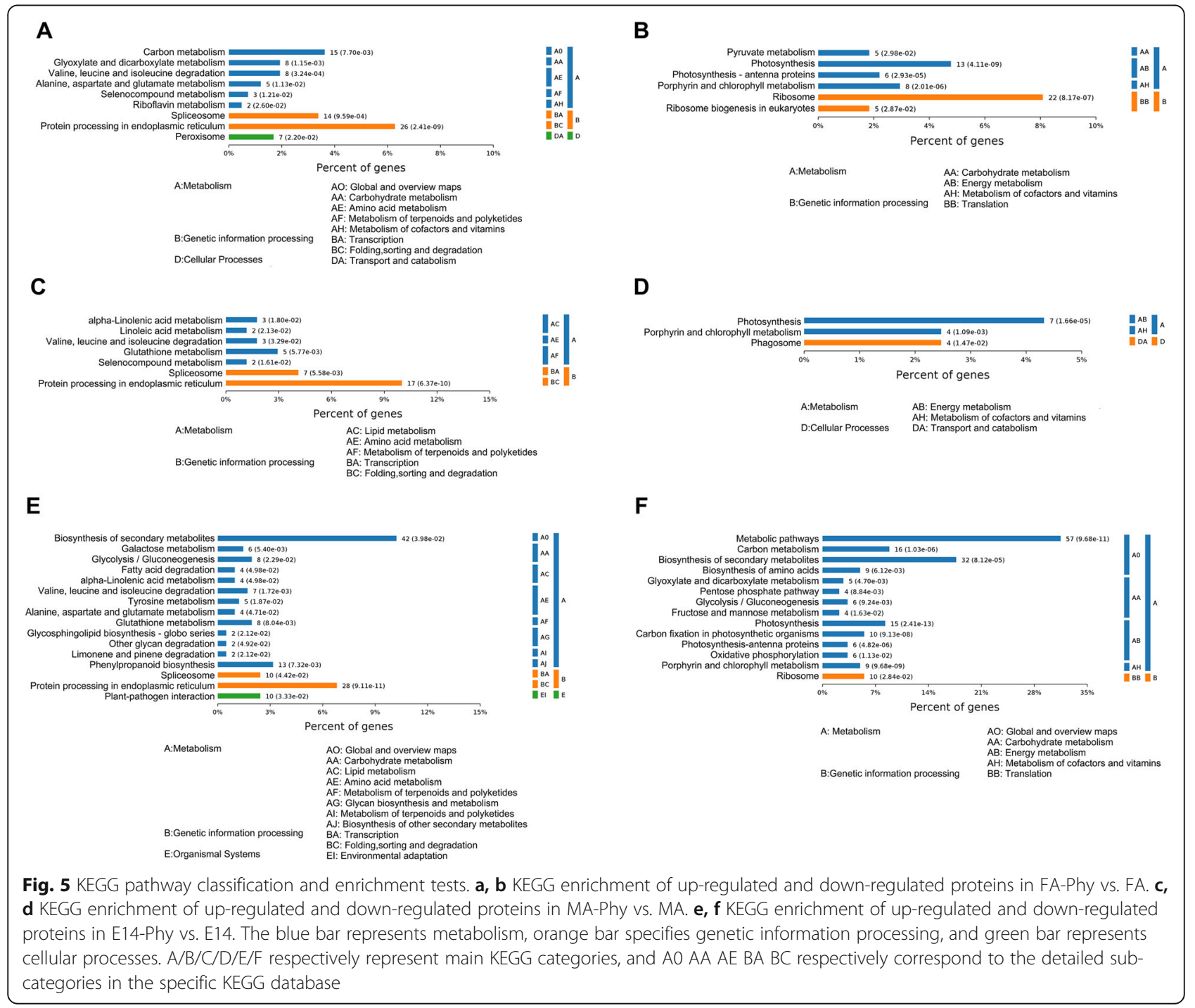



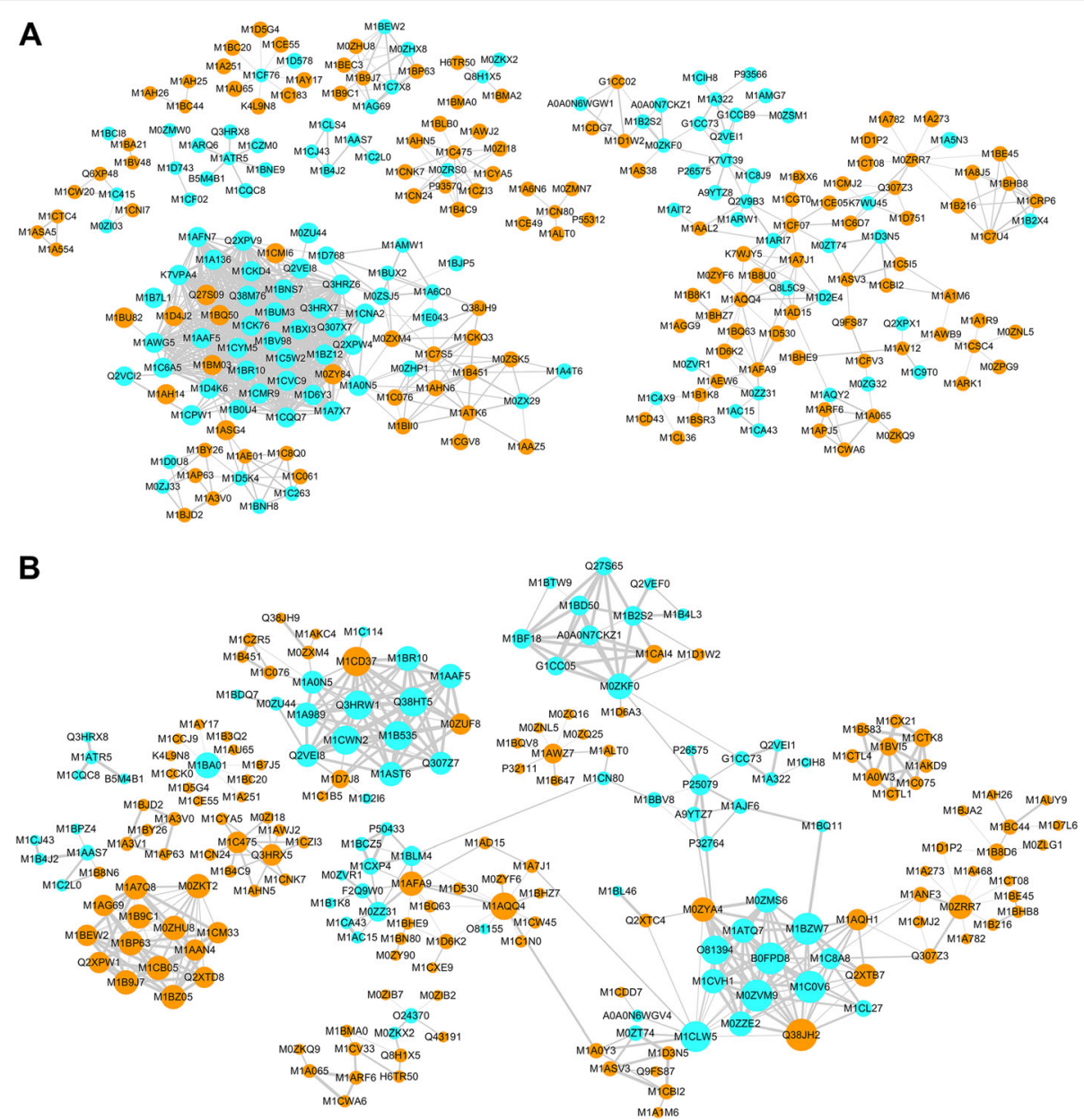

Fig. 6 Protein-protein interaction network. a Network interactions of differentially regulated proteins in FA after PI infection. b Network interactions of differentially regulated proteins in E14 after PI inoculation. Up-regulated proteins are represented by turquoise color and orange color represented down-regulated proteins

Validation of differentially abundant proteins by westernblot and qPCR

To complement and validate the iTRAQ-based proteomics analysis at the translation level, western blotting assays were performed to check BLS1(Serine/threonineprotein phosphatase), CLP1(Protein CLP1 homolog), GST (Probable glutathione S-transferase, Annexin) level in E14-Phy and CHI (endochitinase) level in FA-Phy (Fig. 7a-d). As shown in Fig. 7a and b, the significant increase in abundance levels of three proteins I6XKY2/ BLS1 $(\mathrm{FC}=1.2), \mathrm{M} 1 \mathrm{CYZ7/CLP1}(\mathrm{FC}=1.22)$ and P32111/ GST $(\mathrm{FC}=1.29)$ and Q2HPK8/CHI $(\mathrm{FC}=1.38)$ from ITRAQ analysis was consistent with western blot results for example P32111/GST increase about two-folds (from 0.45 to $0.8, p=0.0002$ ) in E14-Phy compared to E14, also I6XKY2/BLS1 was upregulated in infected plants (from 0.25 to $0.4, p=0.0084$ ), and M1CYZ7/CLP1 increased more than 1.5 folds in abundance (from 0.3 to $0.6 \mathrm{p}=$ 0.0026) (Fig. 7c). Similarly, the abundance of Q2HPK8/
CHI (FC = 1.38) (Fig. 7b) was two-folds higher in FAPhy compared to FA from 0.25 to $0.65, p=0.0093$ ) (Fig. $7 d)$. Potato actin represented loading control use to normalized band intensity for the proteins, the original gel images are reported in Additional file 8, Supplementary Fig. S4.

The qPCR analysis was used to confirm the ITRAQ data at the transcript level. We analyzed the relative expression pattern of genes encoding seven representative DAPs. The selected proteins were involved in multiple biological processes, including the stress and defense process, cellular metabolic process, signaling, and transport. As shown in Fig. 8, positive trend correlations between protein and mRNA expression levels were detected for Q07511, M1A8J5, and M1CY45 which suggest that the abundance of these proteins is likely regulated at the transcriptional level. However, the abundance of the Q2VEI0, M1ATR5, M1CVH4, and I2FJZ8 transcripts was the opposite of their protein abundance suggests 


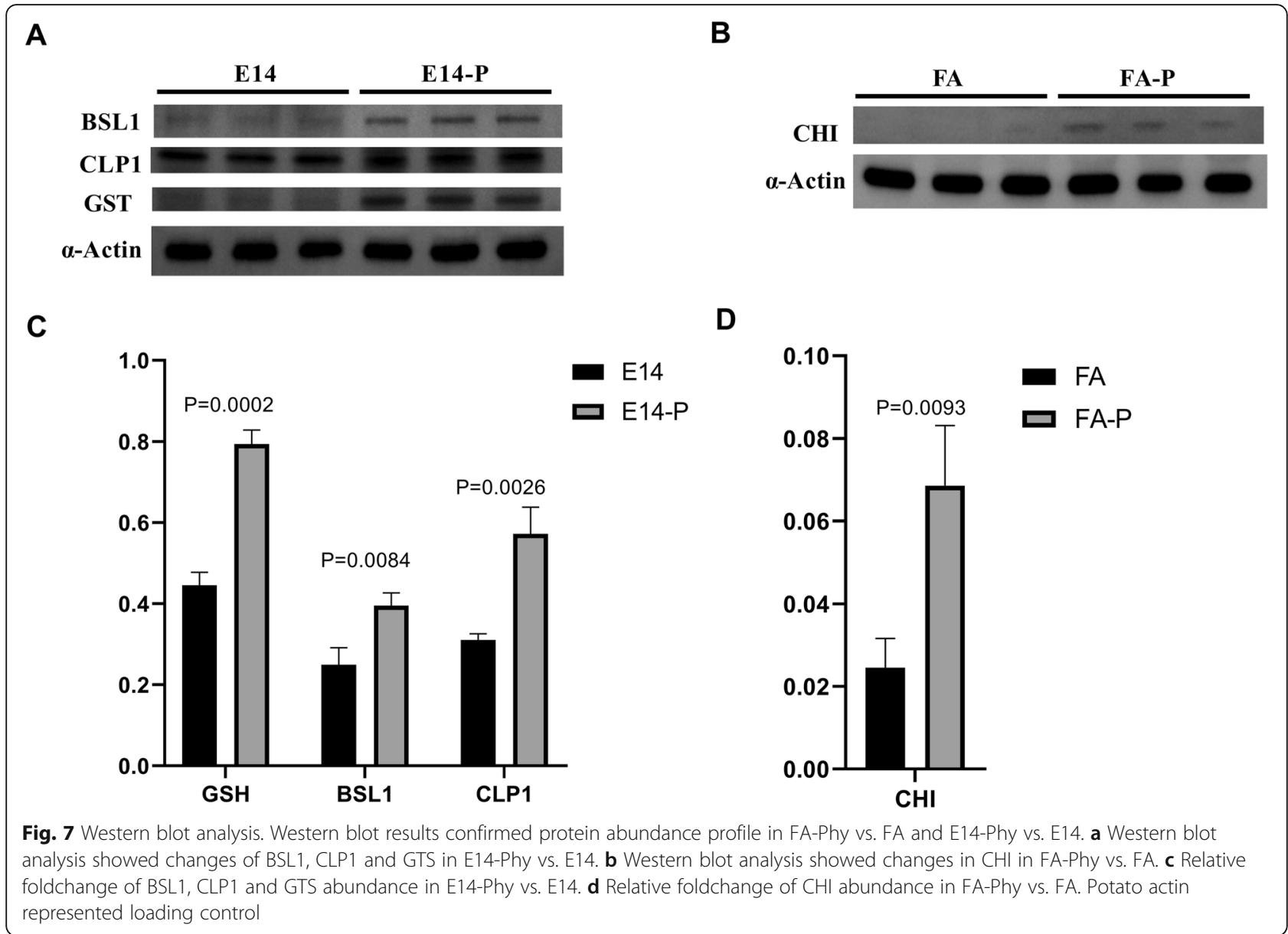

further regulation of these transcripts probably due to posttranslational modifications.

\section{Discussion}

The profile of shared proteins revealed a common response to $\mathrm{PI}$ among the potato cultivars

Locally induced plant responses to pathogenic fungus include accumulation of reactive oxygen species (ROS), hypersensitive reaction (HR), and production of pathogenesis-related (PR) proteins [5, 27]. Our iTRAQ analysis identified proteins shared among the cultivars that have functions related to ROS, HR, and PR respectively. They include two peroxidases (M1AY17 and M1BC20), Endochitinase (Q6B782), a probable linoleate 9S-lipoxygenase 5 (Q43191), LRR receptor-like kinase (A7UE73), small heat shock protein (K7VKA6), and pathogenesis 2-related protein (K7VK61/PR), and four glycosidases (M0ZHI6, M1D7B3, K9MBH7, and P52401), (Table 1). Analysis of protein abundance indicates that these proteins on the average were 1.5-folds higher in abundance compared to control and were consistently up-regulated in the three cultivars (Table 1). Furthermore, GO analysis revealed that these common up-regulated proteins played a role in stress response and defense-related processes.

Among the shared up-regulated proteins, of interest were the peroxidases, endochitinase, PR protein, LRR receptor-like kinase protein, because of their abundance in the three cultivars. For example, Endochitinase usually acts as part of fungal elicitor and plant defense signaling component [24], peroxidases are implicated in pathogen-induced oxidative stress and activation of defense-related activities in potato [28], whereas the LRR receptor-like kinase proteins are involved in perception, recognition, and transmission of external stimulus through signaling cascades to elicit appropriate cellular responses to pathogenic invasion [29]. In the present study, the abundance of A7UE73 was higher in the E14Phy compared to its lower level FA-Phy (Table 1), suggesting weak pathogen recognition in FA-Phy.

Among the shared proteins, we found that proteins related to photosynthesis and "electron transport chain were specifically down-regulated (Table 1 ). They include three photosystem II proteins (G1CC73, Q2VEI0, M1AY18), chlorophyll a-b binding protein, chloroplastic (M1A322), and ferredoxin (Q93XJ9). The suppression of 


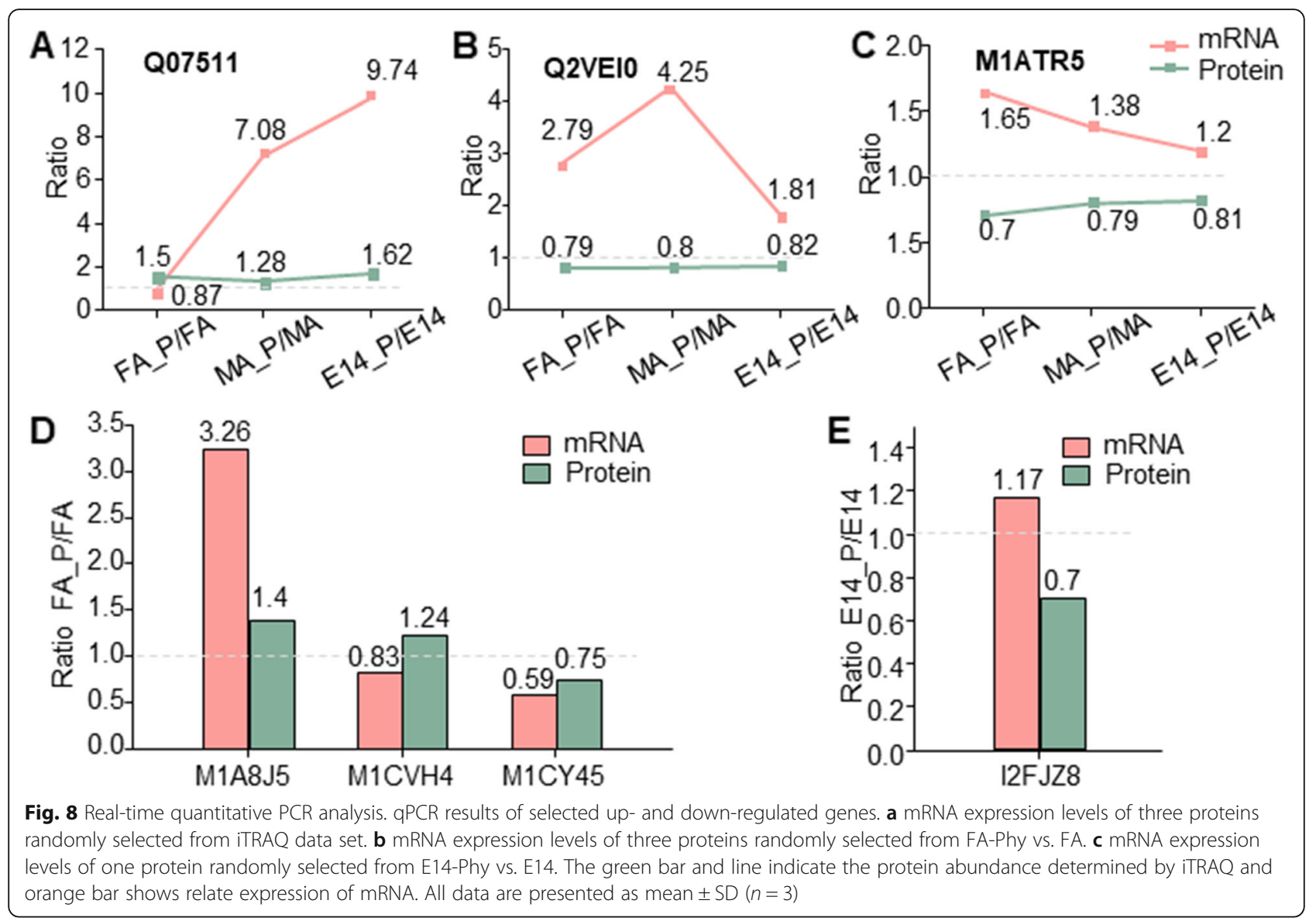

these proteins is consistent with previous studies which show that proteins related to photosynthetic pathways are down-regulated in potato during PI invasion [24, 30].

\section{Dynamic reprogramming of shared proteins revealed potential cultivar specific reaction to $\mathrm{PI}$}

Overlap of the iTRAQ data set revealed15 proteins shared by the cultivars which were reprogrammed after PI infection (Table 1). Among them, a non-specific lipid transfer protein $(\mathrm{M} 1 \mathrm{BBH} 5)$ and an uncharacterized protein belonging to the ataxin-3 family (M1BNE8), were up-regulated in FA-Phy but down-regulated in MA-Phy. The class II chitinase (Q43834), chymotrypsin inhibitor (P01052), Kunitz-type protease inhibitor KTI (M1LA62), abscisic stress/wound-induced protein DS2 (Q8H0L9), and Histone H2B (M1AG69), were up-regulated in MAPhy but repressed in FA-Phy. At the same time, chymotrypsin inhibitor, and DS2 protein were down-regulated in E14-Phy. Here, our result showed that the abundance of protease inhibitors and wound-induced proteins in MA-Phy correlates with host response against pathogenic infection [31, 32]. Furthermore, allene oxide cyclase (Q8H1X5) and two uncharacterized proteins M1D768 and M1D478 containing alpha/beta knot methyltransferases domain were consistently downregulated in FA-Phy and MA-Phy, opposite to their high induction in the E14-Phy. Previous studies have shown that allene oxide synthase (AOS) catalyzes the first reaction leading to the formation of jasmonates and jasmonic acid (JA). JAs are known to mediate defense responses against pathogenic fungus [33, 34]. Here, it is likely that JA canonical pathway was highly induced E14-Phy and might contribute to the resistant phenotype of E14-Phy in contrast to FA-Phy. Together, these results highlight the difference in each cultivar response to PI.

\section{FA proteins specifically targeted by late blight disease pathogen $P$. infestans}

Analysis of FA proteome response to PI infection revealed specific repression of defense proteins, proteins involved in primary metabolism, and hormone signaling process. For instance, nine uncharacterized proteins (M1CLH3, M1BN73, M1DR90, M1AJH8, M0ZJT7, M1BAU5, M1C4P4, M1BAU6, and M1ACY3) containing pathogenesis-related protein Bet $\mathrm{v}$ I (PR) binding domain were specifically down-regulated in FA-Phy with very high negative foldchange (Table 1). PR-related 
Table 1 Proposed candidate protein functionally related to susceptible, tolerance, and resistance of late blight disease in potato

\begin{tabular}{ll}
\hline Accession & Description \\
& \\
\hline Common DAPs & up-regulated in FA-Phy, MA-Phy and E14-Phy \\
K7VKA6 & 17.6 kDa class 1 small heat shock protein \\
K7VK61 & Pathogenesis-related protein P2 \\
M1AY17 & Peroxidase \\
M1BC20 & Peroxidase \\
Q6B782 & Endonuclease \\
Q43191 & Probable linoleate 9S-lipoxygenase 5 \\
A7UE73 & LRR receptor-like kinase \\
M0ZH16 & Beta-galactosidase \\
M1D7B3 & Beta-galactosidase \\
K9MBH7 & Beta-1,3-glucanase 22 \\
P52401 & Glucan endo-1,3-beta-glucosidase, basic isoform 2
\end{tabular}

\begin{tabular}{l} 
FA-Phy \\
\hline Fold $P$ value \\
Change
\end{tabular}

MA-Phy

Fold $P$ value

Change

E14-Phy

Change

Common DAPs down-regulated in FA-Phy, MA-Phy and E14-Phy

$\begin{array}{ll}\text { G1CC73 } & \text { Photosystem II protein D1 } \\ \text { Q2VEI0 } & \text { Photosystem II CP43 reaction center protein } \\ \text { M1AY18 } & \text { Chlorophyll a-b binding protein, chloroplastic } \\ \text { M1A322 } & \text { Cytochrome b559 subunit alpha } \\ \text { Q93XJ9 } & \text { Ferredoxin }\end{array}$

\section{Protein reprogrammed in FA-Phy, MA-Phy and E14-Phy}

$\begin{array}{ll}\text { M1BBH5 } & \text { Non-specific lipid-transfer protein } \\ \text { M1BNE8 } & \text { Uncharacterized protein } \\ \text { P01052 } & \text { Chymotrypsin inhibitor I, A, B and C subunits } \\ \text { Q8H0L9 } & \text { DS2 protein } \\ \text { Q43834 } & \text { Class II chitinase } \\ \text { M1LA62 } & \text { Kunitz-type protease inhibitor D (Fragment) } \\ \text { M1AG69 } & \text { Histone H2B } \\ \text { Q8H1X5 } & \text { Allene oxide cyclase } \\ \text { M1D768 } & \text { Uncharacterized protein } \\ \text { M1D478 } & \text { Uncharacterized protein }\end{array}$

\section{FA specific proteins altered by PI}

$\begin{array}{ll}\text { M1CLH3 } & \text { Uncharacterized protein containing PR-like domain } \\ \text { M1BN73 } & \text { Uncharacterized protein containing PR-like domain } \\ \text { M1DR90 } & \text { Uncharacterized protein containing PR-like domain } \\ \text { M1AJH8 } & \text { Uncharacterized protein containing PR-like domain } \\ \text { M0ZJT7 } & \text { Uncharacterized protein containing PR-like domain } \\ \text { M1BAU5 } & \text { Uncharacterized protein containing PR-like domain } \\ \text { M1C4P4 } & \text { Uncharacterized protein containing PR-like domain } \\ \text { M1BAU6 } & \text { Uncharacterized protein containing PR-like domain } \\ \text { M1ACY3 } & \text { Uncharacterized protein containing PR-like domain } \\ \text { Q307X7 } & \text { Ribosomal protein PETRP-like } \\ \text { Q2XPV9 } & 40 S \text { ribosomal protein S8 } \\ \text { Q3HRZ6 } & 40 \text { S ribosomal protein S8 }\end{array}$

$\begin{array}{llllll}3.82 & 0.00 & 3.67 & 0.00 & 2.54 & 0.00 \\ 1.35 & 0.00 & 1.46 & 0.00 & 2.53 & 0.00 \\ 2.37 & 0.00 & 1.29 & 0.00 & 2.34 & 0.00 \\ 1.36 & 0.00 & 1.27 & 0.00 & 1.41 & 0.00 \\ 2.50 & 0.00 & 1.70 & 0.02 & 2.77 & 0.00 \\ 2.02 & 0.00 & 1.47 & 0.00 & 2.25 & 0.00 \\ 1.44 & 0.00 & 1.21 & 0.04 & 1.70 & 0.00 \\ 1.91 & 0.00 & 1.35 & 0.00 & 1.75 & 0.00 \\ 2.38 & 0.00 & 1.23 & 0.03 & 2.21 & 0.00 \\ 2.30 & 0.00 & 1.27 & 0.00 & 2.10 & 0.00 \\ 2.46 & 0.00 & 1.39 & 0.02 & 2.79 & 0.00 \\ & & & & & \\ 0.82 & 0.00 & 0.74 & 0.00 & 0.83 & 0.00 \\ 0.79 & 0.00 & 0.80 & 0.00 & 0.82 & 0.00 \\ 0.76 & 0.00 & 0.81 & 0.00 & 0.65 & 0.00 \\ 0.83 & 0.00 & 0.81 & 0.01 & 0.70 & 0.00 \\ 0.80 & 0.02 & 0.76 & 0.00 & 0.63 & 0.00 \\ & & & & & \\ 1.39 & 0.01 & 0.72 & 0.01 & 1.25 & 0.02 \\ 1.34 & 0.00 & 0.77 & 0.00 & 0.75 & 0.00 \\ 0.62 & 0.00 & 1.70 & 0.00 & 0.57 & 0.00 \\ 0.58 & 0.01 & 1.22 & 0.00 & 0.62 & 0.00 \\ 0.78 & 0.03 & 1.60 & 0.00 & 1.77 & 0.00 \\ 0.74 & 0.00 & 1.95 & 0.00 & 1.21 & 0.00 \\ 0.78 & 0.00 & 1.30 & 0.00 & 1.27 & 0.00 \\ 0.83 & 0.00 & 0.79 & 0.00 & 1.20 & 0.00 \\ 0.64 & 0.00 & 0.68 & 0.00 & 1.34 & 0.00 \\ 0.65 & 0.00 & 0.53 & 0.00 & 1.32 & 0.00 \\ & & & & \end{array}$

$\begin{array}{llllll}1.31 & 0.03 & - & - & - & - \\ 0.75 & 0.00 & - & - & - & - \\ 0.52 & 0.00 & - & - & - & - \\ 0.55 & 0.05 & - & - & - & - \\ 0.80 & 0.00 & - & - & - & - \\ 0.63 & 0.02 & - & - & - & - \\ 0.60 & 0.00 & - & - & - & - \\ 0.75 & 0.00 & - & - & - & - \\ 0.58 & 0.01 & - & - & - & - \\ 0.81 & 0.00 & - & - & - & - \\ 0.78 & 0.00 & - & - & - & - \\ 0.78 & 0.00 & - & - & - & -\end{array}$


Table 1 Proposed candidate protein functionally related to susceptible, tolerance, and resistance of late blight disease in potato (Continued)

\begin{tabular}{|c|c|c|c|c|c|c|c|}
\hline \multirow[t]{2}{*}{ Accession } & \multirow[t]{2}{*}{ Description } & \multicolumn{2}{|l|}{ FA-Phy } & \multicolumn{2}{|l|}{ MA-Phy } & \multicolumn{2}{|l|}{ E14-Phy } \\
\hline & & $\begin{array}{l}\text { Fold } \\
\text { Change }\end{array}$ & $P$ value & $\begin{array}{l}\text { Fold } \\
\text { Change }\end{array}$ & $P$ value & $\begin{array}{l}\text { Fold } \\
\text { Change }\end{array}$ & $P$ value \\
\hline Q3HRX7 & Ribosomal protein L25-like protein & 0.77 & 0.01 & - & - & - & - \\
\hline M1D4K6 & Ribosomal protein L19 & 0.73 & 0.00 & - & - & - & - \\
\hline K7VPA4 & Ribosomal protein L24 & 0.70 & 0.00 & - & - & - & - \\
\hline Q2XPW4 & 605 ribosomal protein L7A-like protein & 0.69 & 0.00 & - & - & - & - \\
\hline M1CGC9 & 3-phosphoshikimate 1-carboxyvinyltransferase & 0.78 & 0.00 & - & - & - & - \\
\hline M1BTT7 & Ketol-acid reductoisomerase & 0.78 & 0.00 & - & - & - & - \\
\hline M1AIT2 & D-3-phosphoglycerate dehydrogenase & 0.79 & 0.00 & - & - & - & - \\
\hline M1CZCO & ERBB-3 BINDING PR & 0.81 & 0.00 & - & - & - & - \\
\hline A0A0M4KNM3 & Carotenoid $9,10\left(9^{\prime}, 10^{\prime}\right)$-cleavage dioxygenase 1 -like protein (Fragment) & 0.77 & 0.00 & - & - & - & - \\
\hline Q9ZRB6 & Ci21A protein & 0.38 & 0.00 & - & - & - & - \\
\hline K7VKB1 & TAS14 peptide & 0.42 & 0.00 & - & - & - & - \\
\hline \multicolumn{8}{|c|}{ MA specific proteins induced against PI } \\
\hline A0A097H183 & PIN-I protein & - & - & 2.24 & 0.00 & - & - \\
\hline Q3S492 & Proteinase inhibitor I & - & - & 1.47 & 0.00 & - & - \\
\hline A0A097H193 & PIN-II protein & - & - & 1.44 & 0.03 & - & - \\
\hline EOWCF2 & Type I serine protease inhibitor & - & - & 1.85 & 0.00 & - & - \\
\hline J7EQ46 & Proteinase inhibitor II type C-b & - & - & 1.73 & 0.00 & - & - \\
\hline Q41434 & Wound-inducible proteinase inhibitor I (Fragment) & - & - & 1.38 & 0.00 & - & - \\
\hline M1BSA4 & Carboxypeptidase & - & - & 1.35 & 0.00 & - & - \\
\hline P37842 & Multicystatin & - & - & 1.94 & 0.00 & - & - \\
\hline A0A097H108 & KTI-A protein (Fragment) & - & - & 1.47 & 0.01 & - & - \\
\hline A0A097H1 14 & KTI-A protein & - & - & 1.34 & 0.00 & - & - \\
\hline MOZWN2 & Thioredoxin & - & - & 1.23 & 0.00 & - & - \\
\hline Q3HVN5 & Dehydroascorbate reductase & - & - & 1.30 & 0.04 & - & - \\
\hline A2ICR9 & Dehydroascorbate reductase & - & - & 1.23 & 0.00 & - & - \\
\hline A9LMM9 & Dehydroascorbate reductase & - & - & 1.22 & 0.00 & - & - \\
\hline P31212 & Threonine dehydratase biosynthetic (Fragment) & - & - & 1.31 & 0.00 & - & - \\
\hline $\mathrm{M} 1 \mathrm{BC} 24$ & Phospho-2-dehydro-3-deoxyheptonate aldolase & - & - & 1.24 & 0.02 & - & - \\
\hline G91HI3 & Apoplastic invertase & - & - & 0.80 & 0.00 & - & - \\
\hline F2Q9V9 & Glyceraldehyde-3-phosphate dehydrogenase & - & - & 0.82 & 0.01 & - & - \\
\hline M1ALJ6 & Phosphotransferase & - & - & 0.83 & 0.03 & - & - \\
\hline M1BQC2 & Pectinesterase & - & - & 0.82 & 0.00 & - & - \\
\hline Q38JH8 & S-adenosylmethionine synthase 2 & - & - & 0.73 & 0.00 & - & - \\
\hline M1CD27 & Methylthioribose-1-phosphate isomerase & - & - & 0.79 & 0.01 & - & - \\
\hline M1BTK3 & Potassium transporter & - & - & 0.74 & 0.01 & - & - \\
\hline M1BM79 & Ammonium transporter & - & - & 0.76 & 0.00 & - & - \\
\hline \multicolumn{8}{|c|}{ E14 specific proteins deployed against PI } \\
\hline P52403 & Endochitinase 1 (Fragment) & - & - & - & - & 3.56 & 0.00 \\
\hline 081144 & Class I chitinase & - & - & - & - & 1.33 & 0.01 \\
\hline Q84XG7 & Erwinia induced protein 1 & - & - & - & - & 1.26 & 0.00 \\
\hline M0ZG93 & Mitogen-activated protein kinase & - & - & - & - & 1.20 & 0.01 \\
\hline M1B7J5 & Peroxidase & - & - & - & - & 1.41 & 0.00 \\
\hline
\end{tabular}


Table 1 Proposed candidate protein functionally related to susceptible, tolerance, and resistance of late blight disease in potato (Continued)

\begin{tabular}{|c|c|c|c|c|c|c|c|}
\hline \multirow[t]{2}{*}{ Accession } & \multirow[t]{2}{*}{ Description } & \multicolumn{2}{|l|}{ FA-Phy } & \multicolumn{2}{|l|}{ MA-Phy } & \multicolumn{2}{|l|}{ E14-Phy } \\
\hline & & $\begin{array}{l}\text { Fold } \\
\text { Change }\end{array}$ & $P$ value & $\begin{array}{l}\text { Fold } \\
\text { Change } \\
\end{array}$ & $P$ value & $\begin{array}{l}\text { Fold } \\
\text { Change }\end{array}$ & $P$ value \\
\hline M1B3Q2 & Peroxidase & - & - & - & - & 1.39 & 0.00 \\
\hline M1CCKO & Peroxidase & - & - & - & - & 1.31 & 0.00 \\
\hline M1CCJ9 & Peroxidase & - & - & - & - & 1.23 & 0.00 \\
\hline Q38JB4 & Chloroplast lipocalin & - & - & - & - & 1.22 & 0.01 \\
\hline P32111 & Probable glutathione S-transferase & - & - & - & - & 1.29 & 0.00 \\
\hline Q84U63 & Osmotin-like protein (Fragment) & - & - & - & - & 1.87 & 0.04 \\
\hline Q5XUG9 & Putative thaumatin-like protein & - & - & - & - & 1.43 & 0.01 \\
\hline Q8LRU6 & Pathogenesis related protein 10 (Fragment) & - & - & - & - & 1.38 & 0.03 \\
\hline A0A097H 100 & Clone PI9650 defensin-like protein mRNA & - & - & - & - & 1.46 & 0.00 \\
\hline M1BC19 & RSI1 & - & - & - & - & 1.21 & 0.02 \\
\hline M1BV78 & Peptidylprolyl isomerase & - & - & - & - & 1.22 & 0.00 \\
\hline Q2XTE5 & Hsp90-2-like & - & - & - & - & 1.31 & 0.04 \\
\hline Q3HRX5 & DnaJ-like protein & - & - & - & - & 1.32 & 0.02 \\
\hline 16XKY2 & Serine/threonine-protein phosphatase & - & - & - & - & 1.24 & 0.01 \\
\hline M1CXE9 & Uncharacterized protein & - & - & - & - & 1.44 & 0.00 \\
\hline M1C047 & Uncharacterized protein & - & - & - & - & 1.47 & 0.01 \\
\hline M1AZW1 & Calcium-transporting ATPase & - & - & - & - & 1.22 & 0.00 \\
\hline M1BXT8 & Calcium-transporting ATPase & - & - & - & - & 1.36 & 0.00 \\
\hline MoZSI1 & Importin subunit alpha & - & - & - & - & 1.37 & 0.00 \\
\hline M1B7C9 & Importin subunit alpha & - & - & - & - & 1.22 & 0.02 \\
\hline M1C203 & Vacuolar protein sorting-associated protein 35 & - & - & - & - & 1.42 & 0.00 \\
\hline M1C203 & Vacuolar protein sorting-associated protein 35 & - & - & - & - & 1.42 & 0.00 \\
\hline M1DLL0 & Protein transport protein Sec61 subunit beta & - & - & - & - & 1.20 & 0.00 \\
\hline
\end{tabular}

proteins are antimicrobial proteins induced by the host against the pathogen [35]. The suppression of PR proteins suggests that PI compromised the FA-Phy defense system.

Additionally, proteins that constitute ribosomal subunits such as PETRP-like (Q307X7), 40S-RPS8 (Q2XPV9, and Q3HRZ6), RPL25-like protein (Q3HRX7), RPL19 (M1D4K6), RPL24 (K7VPA4), and 60S RPL7A-like protein (Q2XPW4), were suppressed by PI in FA-Phy (Table 1). One study suggests that RPL12 and RP-L19 play a role in non-host resistance against the pathogen [36]. In the present study, the downregulation of many ribosomal proteins suggests that PI diminished basal defense mechanism in FA-Phy, which is in agreement with the phenotype of FA-Phy after infection.

Also, we noticed specific suppression of proteins related to aromatic amino acid biosynthesis and metabolisms such as (phosphoshikimate 1-carboxyvinyltransferase (M1CGC9), ketol-acid reductoisomerase (M1BTT7), and D-3-phosphoglycerate dehydrogenase (M1AIT2). The phosphoshikimate 1-carboxyvinyltransferase is a key enzyme of the shikimate pathway, involved in the biosynthesis of multiple aromatic compounds, including chorismite, phenylalanine, tyrosine, and tryptophan [37]. The ketol-acid reductoisomerase belonged to the family of nicotinamide adenine dinucleotide phosphate (NADPH)dependent oxidoreductases, involved in the supply of flux for the metabolism of valine, isoleucine, and leucine [38]. Whereas D-3-phosphoglycerate dehydrogenase catalyzes the reversible oxidation of 3-phospho-D-glycerate to 3phosphonooxypyruvate, the committed step in the pathway of L-serine biosynthesis [39].

Typically, hormones play a vital role in defense/immunity against pathogenic invasion, however, various pathogens also manipulate hormone signaling pathways to alter the plant defense response. In FA-Phy, hormone signaling pathways were also not left out in the onslaught by PI. For instance, we observed a specific down-regulation of ERBB-3 binding protein 1 (M1CZC0/EBP-1) and carotenoid $\left(9^{\prime}, 10^{\prime}\right)$-cleavage dioxygenase 1-like enzyme, (A0A0M4KNM3) involved in hormone signaling. The EBP-1 regulates auxin-mediated 
signal transduction, which promotes growth and development [40], and 9-cis-epoxycarotenoid dioxygenase is an important enzyme for abscisic acid (ABA) biosynthesis [41]. Similarly, two peptides Ci21A and TASI14 (Q9ZRB6 and K7VKB1) involved in ABA-mediated water stress and desiccation [42] were also downregulated by PI.

A growing body of evidence indicates that $R$ genes products require the combined effect of, pathogenesisrelated proteins, hormones, and phenolic compounds in a dose-dependent manner to provide superior or durable resistance against PI [43]. The present results suggest that the significant reduction of PR proteins, as well as the repression of precursors for biosynthesis of hormones and phenolic compounds, promoted PI pathogenesis in FA-Phy, which is in agreement with FA-Phy phenotype (Fig. 1).

\section{MA specific response to late blight disease pathogen $P$. infestans}

A typical outcome of potato-PI incompatible interaction is the development of localized $\mathrm{HR}$ [24, 27]. In this study, MA-Phy developed few macroscopic HR lesions compared to FA-Phy (Fig. 1), probably due to the induction of antifungal proteins uniquely specific to MA. Indeed, most of the defense-related proteins were positively induced and include a group of protease inhibitors and antifungal peptides such as PIN-I (A0A097H183 and Q3S492), PIN-A (A0A097H193), PIN-II (E0WCF2), PIN II- type C-b (J7EQ46), wound-inducible proteinase inhibitor I (Q41434), carboxypeptidase enzyme (M1BSA4), multicystatin (P37842), and Kunitz-type soybean trypsin inhibitor (KTI) protein (A0A097H108 and A0A097H114) (Table 1). The accumulation of several protease inhibitors in MA-Phy is consistent with reports that suggest a battery of proteolytic enzyme inhibitors, enzyme regulators, and peptidase inhibitors are upregulated to overcome PI during potato-PI incompatible interaction [43-45]. Also, enzymes involved in antioxidant activity accumulated in MA-Phy, for example, thioredoxin (MOZWN2) and dehydroascorbate reductases (Q3HVN5, A2ICR9, and A9LMM9) were highly up-regulated. Thioredoxins participate in the defense against cellular oxidative damage [46], and dehydroascorbate reductases are involved in scavenging radicals and non- oxygen radicals [47].

Several proteins involved in secondary metabolism were positively induced, but we focused on two proteins threonine dehydratase (P31212) and Phospho-2-dihydro-3deoxyheptonate aldolase (M1BC24) related to the shikimate pathway. Threonine dehydratase is the first enzyme in L-isoleucine biosynthesis, catalyzing deamination and dehydration of threonine to produce 2-ketobutyrate and ammonia. One report indicates that this enzyme is induced in response to wounding, abscisic acid, and jasmonic acid signaling [48]. The Phospho-2-dihydro-3deoxyheptonate aldolase catalyzes the first step of chorismate biosynthesis and is a part of metabolic intermediates that provides precursors to the phenylpropanoid pathway for the biosynthesis of phenolic compounds.

In contrast, many proteins involved in cellular processes were repressed in MA-Phy. For example, apoplastic invertase (G9IHI3), glyceraldehyde-3-phosphate dehydrogenase (F2Q9V9/GAPDH), phosphotransferase (M1ALJ6), and pectinesterase (M1BQC2). The apoplastic invertase is a member of the glycoside hydrolase family that catalyzes the hydrolysis of sucrose into fructose and glucose, (Niki et al., 1998). The GAPDH is involved in the breakdown of glucose to produce energy and carbon molecules [49]. The suppression of GAPDH could lead to a reduction in the carbon source available for pathogenic growth. The phosphotransferases belong to the hexokinase family and are involved in cellular glucose homeostasis [50]. The pectinesterase is a cell wall modifying enzyme, involved in pectin degradation [51]. The significant decrease in abundance of these carbon and energy-generating enzymes could be part of a MA defense system to contain the invading pathogen.

Interestingly, we found that $\mathrm{S}$-adenosylmethionine synthase 2 (Q38JH8) and methylthioribose-1-phosphate isomerase (M1CD27) were also repressed. Both enzymes are critical components of the methionine salvage system which can be used for the production of ethylene, cysteine, and other sulfur-containing amino acids [52]. Sauter et al., [53] reported that pathogenic microbes are capable of exploiting a range of organic and inorganic sulfur within the host. In the present study, the depression of enzymes of the methionine salvage pathway resembles a host defense mechanism geared towards restricting PI growth by reducing sulfate sources. Furthermore, methionine is a precursor for the biosynthesis of ethylene and other polyamines [54], although the role of ethylene in plant-pathogen interaction is still unclear. One report suggests that pathogens manipulate ethylene biosynthesis to promote pathogenicity in host plants [40]. For example, ethylene was shown to promote compatible interaction between $P$. pyrifolia and a necrotrophic fungus Alternaria alternata [55]. But, in other pathosystems, ethylene was shown to mediate incompatible interaction [40]. In this study, therefore, it is likely that PI infection resulted in host attenuation of ethylene biosynthesis in MA.

To be successful, most fungal pathogens exploit sources of the nutrients within their host to support growth. In the MA-Phy, two transport proteins: potassium transporter (M1BTK3) and ammonia transporter (M1BM79) were down-regulated. Ammonium and urea are essential nitrogen sources for many pathogens, 
including fungus, and the accumulation of these compounds has been associated with pathogenicity [56]. Here, the decrease in abundance of nutrient transporters by the host seems to be part of the MA defense strategy for suppressing PI growth.

Together these results highlight the potential role of protease inhibitors, antioxidants, aromatic compounds in MA defense protein machinery against PI opposite to the phenotypic and molecular response observed in FA.

\section{E14 specific response to late blight disease pathogen $P$. infestans}

Evaluation of E14 proteome specific response to PI infection revealed strong pathogen recognition and efficient activation of immune response against PI. Proteins responsible for PI recognition and defense signaling components were up-regulated in E14-Phy after infection. In particular, the two endochitinases (P52403 and O81144), erwinia induced protein 1 (Q84XG7/Ei1), and mitogen-activated protein kinase (M0ZG93/MAPK) (Table 1). Generally, chitinases are typically induced as a part of defense machinery against chitin-containing fungal pathogens [57]. Ei1 contained the LysM domain, a small globular domain that can bind peptidoglycan and chitin containing microbes [58]. Here, we suspect that Ei1 might be a specific elicitor or PI recognition factor in E14-Phy. The MAPKs are prominent defense signaling proteins involved in the transduction of specific immune reaction against PI [59].

The proteins involved in scavenging of reactive oxygen species (ROS) and detoxification of microbial compounds were also specifically abundant and perhaps up-regulated in response to PI by E14-Phy (Table 1). They include four peroxidases; (M1B7J5, M1B3Q2, M1CCK0, and M1CCJ9), a chloroplast lipocalin protein (Q38JB4), a probable glutathione S-transferase (P32111/GSTs), osmotin-like protein (Q84U63), thaumatin-like protein (Q5XUG9), and pathogenesis-related protein 10 (Q8LRU6/PR-10). GSTs have an antioxidative effect against oxidative stress [60] and the abundance of the protein was confirmed by western blot. The osmotin and thaumatin produce antifungal activity [61], and PR proteins are highly induced during microbial infection and wounding [62].

Like in the MA-Phy, several protease inhibitors accumulated in E14-Phy after PI infection (Table 1). The most prominent among them is the Clone PI9650 defensin-like protein mRNA (A0A097H100), an antifungal peptide that belongs to the defensin family, and involved in innate immune system response directed primarily against fungal pathogens [63]. Another defense-associated protein specifically induced by PI infection is the RSI1 (M1BC19). RSI1 is a membrane-bound protein similar to prohibitin and contains a band7 domain. The specific function of the RSI1- band7 domain during potato-P. infestans interaction is unclear. However, in Arabidopsis, RSI1 was shown to encode putative histone demethylase that interacts with GSTT2 and WRKY transcription factors to activate systemic acquired resistance (SAR) against the pathogen [60]. We equally noticed the induction of peptidylprolyl isomerase PPIase (M1BV78). PPIases are categorized as immunophilins/immunosuppressive ligands, that mediate protein-to-protein interaction, as well as heat-stress, and pathogen virulence-associated factors [64]. Here, the direct role of PPlase during E14-PI interaction is unclear, however, we speculate that it might be involved in the protein modification process or participate in the signal transduction of immune response.

Furthermore, proteins associated with heat stress, hormone signaling, and transcription factor activity were also abundant in E14-Phy (Table 1). For example, two heat shock binding proteins (Q2XTE5 and Q3HRX5/ HSPs), serine/threonine-protein phosphatase (I6XKY2/ BLS1), and two uncharacterized proteins containing Ornithine aminotransferase (M1CXE9/OAT) and a WRKY (M1C047) domain respectively. HSPs maintain the folding of newly synthesized proteins, stabilization, and refolding of denatured proteins during heat stress [65]. The BLS1 is a member of the phosphoprotein phosphatase (PPP) family, involved in multi-diverse processes including brassinosteroid signaling, auxin signaling, ROS signaling, and defense response [66]. The OAT is involved in proline biosynthesis and proline is implicated in multiple defenses and stresses tolerance process, including hormone signaling and programmed cell death [67]. WRKY transcription factors regulate diverse physiological processes, including pathogen defense, stress responses, senescence, trichome development, and the biosynthesis of secondary metabolites [68].

Additionally, several proteins related to transport were equally abundant in E14-Phy. They include two calciumtransporting ATPase (M1AZW1 and M1BXT8), two Importin subunit alphas (M0ZSI1and M1B7C9), vacuolar protein sorting-associated protein (M1C203/VSP), and transport protein Sec61 subunit beta (M1DLL0) (Table 1). GO analysis showed that the calcium-transporting ATPases are involved in ATP coupled calcium transmembrane transport. Many studies have linked calcium signaling to plant stress responses, particularly the induction of specific plant immunity against pathogens [69]. The importins belong to the karyopherin-alpha family involved in nuclear-cytoplasmic transport of macromolecules including hormones and phytoalexins decrease infection [70] (Chandra, 2012). The VSP is an endosomal polypeptides transporter necessary for protein translocation in the endoplasmic reticulum (ER) [71], and the Sec61 is an ERlocalized protein that mediates the translocation of signal peptides. These proteins could be important for delivering defense-related protein complexes to the site of 
pathogenic invasion. Similarly, [72]. Based on these results we propose a model for the E14-Phy phenotype after PI inoculation (Fig. 9). In this model, the specific accumulation of defense proteins such as endochitinases, Ei1, HSPs, MAPKs, GSTs, WRKY transcription factor, BR, and $\mathrm{Ca}+$ signaling indicate E14-Phy deployed a strong specific immune response against PI, which underpinned the resistant phenotype observed in E14-Phy in contrast to FA-Phy.

\section{Summary}

In this study, we applied ITRAQ-based quantitative proteomics to characterize the response of three Chinese potato cultivars: Favorita (FA), Mira (MA), and Emalingshu N0.14 (E14) infected with late blight disease pathogen $P$. infestans. After inoculation, phenotypic observations revealed that Favorita is susceptible, Mira is tolerant, and E-malingshu N0.14 is immune to late blight disease pathogen. The examination of protein abundance pattern identified potato proteins that were directly altered by the pathogen in the three cultivars, they include shared that were differentially regulated as well as cultivar specific proteins that were induced or repressed in response to PI. GO and KEGG analysis highlighted significant differences and similarities between these three cultivars in terms of defense response to the late blight disease pathogen. Specifically, we identified potato proteins that might be essential to establish tolerance and immunity against late blight disease pathogen $P$. infestans. For example, the repression of PR proteins, ABA, and shikimate pathway in FA-Phy boosted LBD susceptibility in FA plants. Whereas the induction of antimicrobial proteins, antioxidants, protease inhibitors, phenylpropanoid pathway, and repression of nutrient transport proteins enhanced PI tolerance in MA-Phy. Likewise, the induction of immune responses such as LRR receptor-like kinases, mitogen-activated protein kinase, serine/threonine kinases, enzyme regulators, WRKY transcription factors, terpenoid and polyketides, hormone signaling, and transport proteins specified immunity in E14-Phy. These proteins reported in this study are a valuable resource that can be used for developing tolerant and resistant varieties in potato breeding.

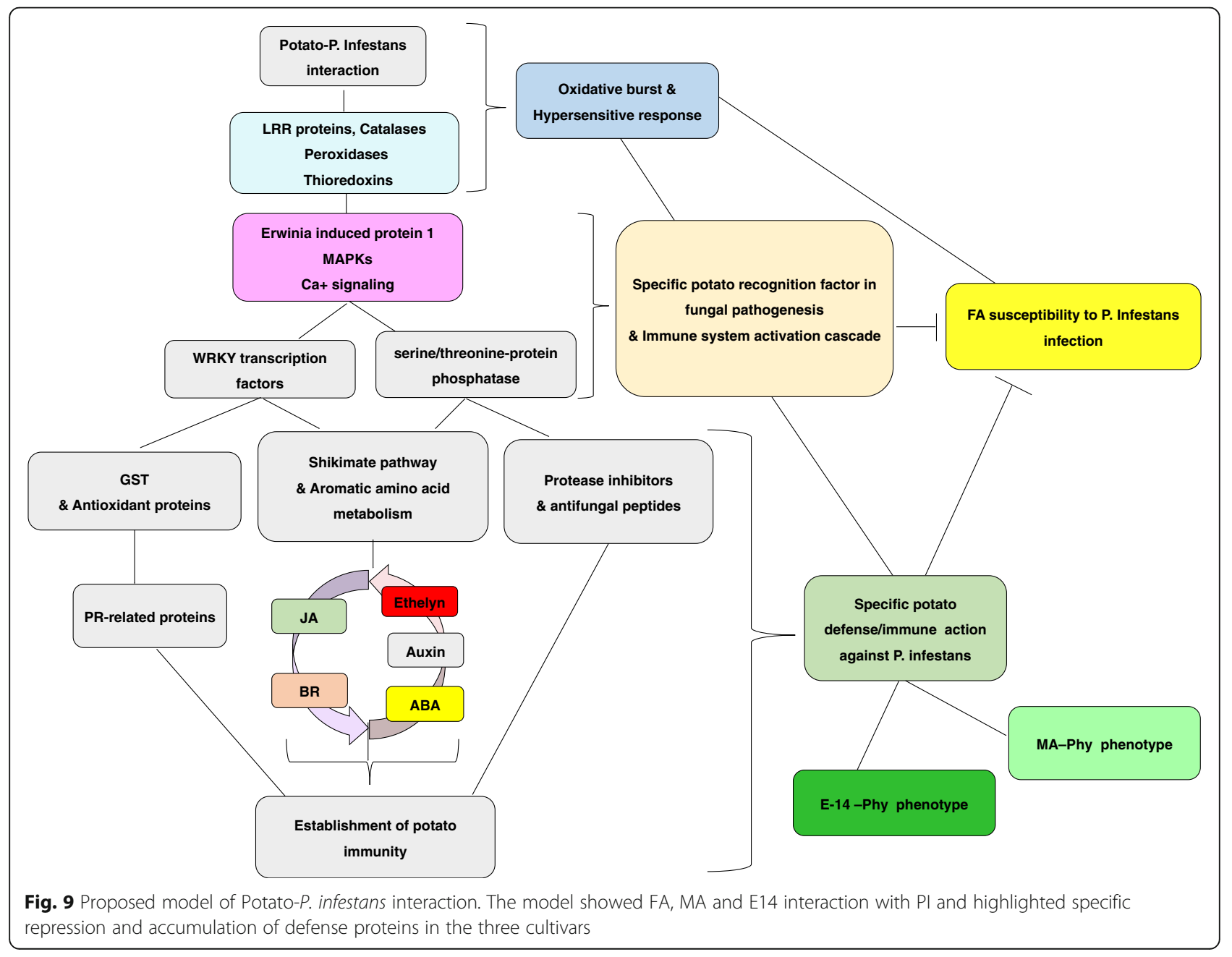




\section{Methods}

\section{Plant materials and sample preparation}

All the plant materials were originally possessed by Southern Potato Research Center of China, Enshi, Tujia and Miao Autonomous Prefecture, Hubei Province. The experimental research on the potato plants including sample collection was performed under institutional guidelines under the local legislation. The Favorita (FA), Mira (MA), and E-malingshu NO. 14 (E14) plants were sowed in a control room with growing conditions set at $20{ }^{\circ} \mathrm{C}, 16: 8$ light to dark cycle, and $70 \%$ relative humidity. At the 5-leaf stage, potato plants were divided into three groups of control plants (FA, MA, and E14) and three groups of FA, MA, and E14 plants inoculated with PI. Hereafter FA-Phy, MA-Phy, and E14-Phy. Each group contained six replicates. Inoculation was performed by spraying the whole plant with an encysted zoospore suspension from the same PI isolate until leaf surfaces were saturated with the zoospore suspension (15,000 sporan$\mathrm{gia} / \mathrm{ml}$ ). The control groups were sprayed with water. To ensure pathogenic infection, the humidity was maintained at $100 \%$ for two days after inoculation and then adjusted to $90 \%$ for the rest of the experiment. For each cultivar, the control and the inoculated group samples were harvested in triplicates, 5 days after inoculation. For each replicate, three to four samples of fully expanded upper leaves were collected. All the materials were rapidly frozen in liquid nitrogen and stored at $80{ }^{\circ} \mathrm{C}$ until use.

\section{Protein extraction, digestion, and ITRAQ labeling}

Protein extraction was performed according to the method described by [73]. Briefly, all samples (FA, MA, and E14) and (FA-Phy, MA-Phy, and E14-Phy) were finely ground in liquid nitrogen, then the proteins were extracted following the procedure described by [36]. The samples are quickly transferred to a pre-chilled $1.5 \mathrm{~mL}$ centrifuge tube in liquid nitrogen, and $1 \mathrm{~mL}$ of prechilled 10\% TCA / acetone (containing $65 \mathrm{mM}$ DTT) was added to each sample and was kept at $-20{ }^{\circ} \mathrm{C}$ in the refrigerator for $2 \mathrm{~h}$. Next, the samples were Centrifuged at $12000 \mathrm{~g}, 45 \mathrm{~min}, 4^{\circ} \mathrm{C}$, and the removed supernatant, then add $-20{ }^{\circ} \mathrm{C}$ precooled pure acetone, place in $20^{\circ} \mathrm{C}$ refrigerator for $2 \mathrm{~h}$, afterward centrifuged at 12000 g, $45 \mathrm{~min}, 4^{\circ} \mathrm{C}$, remove supernatant, and this step was repeated three times. The obtained precipitate was lyophilized and about $800 \mathrm{mg}$ of lyophilized powder was transferred to a $1.5 \mathrm{~mL}$ centrifuge tube and add $1000 \mu \mathrm{L}$ of SDT protein lysate (4\% SDS, $100 \mathrm{mM}$ Tris- $\mathrm{HCl}, 100$ $\mathrm{mM}$ DTT, PH8.0) was added, placed in a boiling water bath at $100{ }^{\circ} \mathrm{C}$ for $10 \mathrm{~min}$, and ice bath for $10 \mathrm{~min}$ (35 W $2 \mathrm{~s}$, interval $8 \mathrm{~S}$ ), and then placed in $100^{\circ} \mathrm{C}$ boiling water bath for another $5 \mathrm{~min}$. Finally, samples were centrifuged at $14000 \mathrm{~g}$ for $30 \mathrm{~min}$, and the supernatant was collected and was filtered with a $0.22 \mu \mathrm{m}$ ultrafiltration tube. We used $1 \mu \mathrm{L}$ of the filtrate for quantification by BCA method, the remaining filtrate is stored at $-80^{\circ} \mathrm{C}$.

For each sample, $200 \mu \mathrm{g}$ of protein extracts were denatured and reduced, and the cysteines blocked using iTRAQ reagents (8plex, AB Sciex, CA, USA), according to the manufacturer's protocol. Next, proteins were diluted with five volumes of $50 \mathrm{mM}$ TEAB to reduce urea concentration to $1.4 \mathrm{M}$, and twice digested with trypsin (Thermo Scientific, CA, USA) at a trypsin/protein ratio of $1: 300\left(37^{\circ} \mathrm{C}\right.$, overnight. and then for $\left.3 \mathrm{~h}\right)$. The resulting peptide solution was concentrated in a vacuum centrifuge and diluted with $70 \mu \mathrm{l}$ of $100 \%$ ethanol. Afterward, the digested peptides were labeled with iTRAQ reagents. Samples were then mixed in equal ratios and dried in a vacuum centrifuge to remove the ethanol. Two 8-plex iTRAQ-labelled peptide mixtures were prepared. The first mixture contained proteins extracted from control samples (FA, MA, and E14) while the second mixture contained PI treated samples (FA-Phy, MA-Phy, and E14-Phy), including three biological replicates of isotopic labeling.

\section{Peptide fractionation with high-pH reversed-phase chromatography separation}

Labeled and mixed peptides were subjected to High-pH Reversed-Phase Fractionation in the 1100 Series HPLC Value System (Agilent) equipped with a Gemini-NX (Phenomena, 00F-4453-E0) column $(4.6 \times 150 \mathrm{~mm}$, $3 \mu \mathrm{m}, 110 \AA)$. Peptides were eluted at a flow rate of 0.8 $\mathrm{mL} / \mathrm{min}$. Buffer A consisted of $10 \mathrm{mM}$ Ammonium acetate ( $\mathrm{pH} 10.0)$ and buffer B consisted of $10 \mathrm{mM}$ Ammonium acetate, 90\% v/v CAN ( $\mathrm{pH} 10.0$ ). Buffer A and B were both filter-sterilized. The following gradient was applied to perform separation: 100\% buffer A for $40 \mathrm{~min}$, 0-5\% buffer B for $3 \mathrm{~min}, 5-35 \%$ buffer B for $30 \mathrm{~min}$, 35-70\% buffer B for $10 \mathrm{~min}$. Then, $70-75 \%$ buffer B for $10 \mathrm{~min}, 75-100 \%$ buffer B for $7 \mathrm{~min}, 100 \%$ buffer B for $15 \mathrm{~min}$, and $100 \%$ buffer A for $15 \mathrm{~min}$. The elution process was monitored by measuring absorbance at 214 $\mathrm{nm}$, and fractions were collected every $75 \mathrm{~s}$. Finally, the fractions collected were combined into 10 pools. Each fraction was concentrated via vacuum centrifugation and was reconstituted in $40 \mu \mathrm{L}$ of $0.1 \% \mathrm{v} / \mathrm{v}$ trifluoroacetic acid. All samples were stored at $-80^{\circ} \mathrm{C}$ until further analysis.

\section{LC-MS/MS analysis}

The iTRAQ-labeled samples were analyzed using the Easy-nLC nanoflow HPLC system connected to Orbitrap Elite mass spectrometer (Thermo Fisher Scientific, San Jose, CA, USA). A total of $1 \mu \mathrm{g}$ of each peptides sample was loaded onto the Thermo Scientific EASY column (two columns) using an autosampler at a flow rate of 
$150 \mathrm{~nL} / \mathrm{min}$. The sequential separation of peptides on Thermo Scientific EASY trap column $(100 \mu \mathrm{m} \times 2 \mathrm{~cm}$, $5 \mu \mathrm{m}, 100 \AA, C 18)$ and analytical column $(75 \mu \mathrm{m} \times 25$ $\mathrm{cm}, 5 \mu \mathrm{m}, 100 \AA$, C18) was achieved with a segmented 2 $\mathrm{h}$ gradient from Solvent A ( $0.1 \%$ formic acid in water) to $35 \%$ Solvent B (0.1\% formic acid in $100 \% \mathrm{ACN})$ for 100 min, followed by $35-90 \%$ Solvent B for $12 \mathrm{~min}$ and then 90\% Solvent B for $8 \mathrm{~min}$. The mass spectrometer was operated in positive ion mode, and MS spectra were acquired over a range of 350-2000 m/z. Resolving powers of the MS scan and MS/MS at $100 \mathrm{~m} / \mathrm{z}$ for the Orbitrap Elite were set as 60,000 and 15,000 , respectively. The top sixteen most intense signals in acquired MS spectra were selected for further MS/MS analysis. The isolation window was $1 \mathrm{~m} / \mathrm{z}$, and ions were fragments through higher energy collisional dissociation with normalized collision energies of $35 \mathrm{eV}$. The maximum ion injection time was set at $50 \mathrm{~ms}$ for the survey scan, and $150 \mathrm{~ms}$ for the MS/ MS scans, and the automatic gain control target values for full san modes were set to $10 \times 10-6$ and for MS/MS was $5 \times 104$. The dynamic exclusion duration was 30 s.

\section{Protein identification and quantitation}

MS/MS spectra were searched using the MASCOT engine (Matrix Science, London, UK; version 2.2) embedded into Proteome Discoverer 1.3 (Thermo Electron, San Jose, CA, USA) against UniProt plant database (134, 648 sequences) and the decoy database. Search parameters include: monoisotopic mass; trypsin as cleavage enzyme; two max missed cleavages; iTRAQ 80 plex $(\mathrm{N}$ term), iTRAQ 8 plex (K) and carbamidomethylation of cysteine as fixed modifications; and oxidation of methionine as variable modifications (Additional file 9: Fig. S4). Peptide mass tolerance of $\pm 20 \mathrm{ppm}$ and fragment mass tolerance of $0.1 \mathrm{Da}$ were used for parent and monoisotopic fragment ions, respectively. Results were filtered based on a false discovery rate of (FDR) $\leq 0.01$. Relative quantitative analyses of proteins were based on ratios of iTRAQ reporter ions from all unique peptides representing each protein (Additional file 10: Fig. S5-8). For protein quantitation, each reporter ion channel was summed across all quantified proteins and normalized assuming equal protein loading of all ten samples. The protein ratios of each sample were normalized to the iTRAQ-126 label [74]. The mass spectrometry proteomics data have been deposited to the ProteomeXchange Consortium (http://proteomecentral.proteomexchange. org) via the iProX partner repository [75] with the dataset identifier PXD014647.

\section{Bioinformatics and statistical analysis}

Proteins of $P$-values $<0.05$ by Student T-test and a foldchange of $>1.20$ in abundance between any two groups were considered significant. I.e., in a pairwise comparison between $P$. infestans treated and untreated control samples of each cultivar FA-Phy VS FA; MA-Phy VS MA and E14-Phy VS E14. Only proteins identified by two or more peptides with a $p$-value $<0.05, \geq 1.2$-fold change were classified as differentially abundant proteins. UniProt database (http://www.uniprot.org) [76] and Blast2GO (Version 2.7.2) [77] were used for GO terms classification of DAPs. Enriched GO terms were identified with Fisher's Exact Test and hypergeometric distribution test cutoff of 0.05. Information on the biological pathways of the DAPs was obtained from the Kyoto Encyclopedia of Genes and Genomes pathways database [78]. Visualization of these pathways and enrichment analysis was performed using the KOBAS 2.0 software.

\section{Antibodies and Western-blot analyses}

For western blot, the procedures of electrophoresis, transfer, and immunodetection were performed according to [79]. The primary antibodies used were as follows: antibody for the Serine/threonine-protein phosphatase (I6XKY2, PhytoAB PHY1724S, 1:1000); Protein CLP1 homolog (M1BQC2, PhytoAB PHY0964S, 1:1000); Probable glutathione S-transferase (P32111, PhytoAB PHY1514S, 1:1000); Putative endochitinase (Q2HPK8, PhytoAB PHY1514S, 1:1000). Horseradish peroxidase-conjugated anti-rabbit IgG (Bio-Rad, dilution 1: 5000) were used as secondary antibodies. After immunodetection, the intensity of the immunostained bands was normalized for the total protein intensities measured by Coomassie blue from the same blot [80]. The images were subjected to a densitometric analysis performed using Quantity One software (Bio-Rad).

\section{RNA extraction and quantitative real-time PCR (qPCR)}

Total RNA was extracted from each sample using TRIZOL reagent (Invitrogen, Carlsbad, CA, USA). The RNA quantity and quality were determined with a NanoDrop 2000 spectrophotometer (Thermo, USA) according to the manufacturer's instructions, after which cDNA was synthesized using the PrimeScript Reverse Transcriptase Kit (Takara, Dalian, China) for quantitative real-time polymerase chain reaction (qPCR). The gene-specific primers for the $\mathrm{qPCR}$ are listed in Additional file 2: Table S1. The PCR condition is as follows, 40 cycles of $95^{\circ} \mathrm{C}$ for $15 \mathrm{~s}$ and $60^{\circ} \mathrm{C}$ for $30 \mathrm{~s}$ ). The gene expression levels were quantified relative to the potato efla gene [24] with 2- $\Delta \Delta \mathrm{CT}$ method [81]. Each reaction was performed in three replicates. Primers used for $\mathrm{qPCR}$ are listed in Additional file 8: Table S5. 


\section{Supplementary Information}

The online version contains supplementary material available at https://doi. org/10.1186/s12864-020-07286-3.

Additional file 1: Fig.S1. Protein sequencing statistics. Blue bar represents MS spectrum, PSMs, Peptide, Unique peptide, and Protein in control (FA, MA, E14) and infected potato plants (FA-Phy, Ma-Phy, and E14-Phy).

Additional file 2: Table S1. Complete list of peptides and proteins identified in control (FA, MA, E14) and infected (FA-Phy, MA-Phy, and E14-Phy) potato plants. The list is organized by protein accession number.

Additional file 3: Table S2. Complete list of differentially abundant proteins between control (FA, MA, E14) and infected (FA-Phy, MA-Phy, and E14-Phy). The list is organized by protein accession number.

Additional file 4: Fig. S2. Pearson correlation analysis of biological replicates of control (FA, MA, E14) and infected potato plants (FA-Phy, Ma-Phy, and E14-Phy). The red box indicates a high positive correlation. The blue box indicates a low degree of correlation.

Additional file 5: Table S3. A list of overlapping proteins among the three comparisons in FA-Phy vs. FA, MA-Phy vs. MA, and E14-Phy vs. E14. The list is organized by protein accession number.

Additional file 6: Fig. S3. GO enrichment of biological processes categories. A, B. Up-regulated, and down-regulated DAPs of FA-Phy. C, D. Up-regulated, and down-regulated DAPs enriched in MA-Phy. E, F. Upregulated and down-regulated DAPs enriched in E14-Phy.

Additional file 7: Table S4. A list of proteins associated with KEGG pathways in FA-Phy vs. FA, MA-Phy vs. MA, and E14-Phy vs. E14. The list is organized by protein accession number.

Additional file 8: Table S5. The list of gene-specific primers selected for qRT-PCR analysis. The list is organized by protein accession number.

Additional file 9: Figure S4.

Additional file 10: Figure S5-8.

\section{Abbreviations}

LBD: Late blight disease; PI: Phytophthora infestans; FA: Favorita; MA: Mira; E14: E-malingshu N0.14; R: Resistance; PAMPs: Pathogen-associated molecular patterns; PRRs: Pattern-recognition receptors; PTI: PAMP-triggered immunity; ETS: Effector-triggered susceptibility; NBS: N-terminal nucleotide-binding site; LRR: C-terminal leucine-rich repeat; PCD: Programmed cell death; ITRA Q: Isobaric tags for relative and absolute quantification; TMT: Tandem mass tags; DAPs: Differentially abundant proteins; GO: Gene ontology; qRTPCR: Quantitative real-time polymerase chain reaction; cDNA: complementary deoxyribonucleic acid; RNA: Ribonucleic acid; LC-MS/MS: Liquid chromatography-mass spectrometry

\section{Acknowledgments}

We would like to thank Prof. Weixing Shan from Northwest Agriculture and Forestry University, Prof. Jiehua Zhu from Hebei Agricultural University, Prof. Jiasui Zhan, and Asso. Prof. Wen Zhu from Fujian Agriculture and Forestry University for insightful comments.

\section{Authors' contributions}

$\mathrm{CX}, \mathrm{BL}, \mathrm{YS}$ - conceived and designed the experiments; $\mathrm{CX}, \mathrm{MH}, \mathrm{JG}$, $Z W$ - performed the experiments; DZ, YZ, LY, XY_analyzed the data; BL, YS — contributed reagents/materials/analysis tools: CX, XY, YS — wrote the paper. The author(s) read and approved the final manuscript.

\section{Funding}

This research was supported by Hubei Provincial Specialized Technological Innovation Project (Special Project of Western Hubei Ethnic Group2016AKB052); China Agriculture Research System (CARS-09); Central Guidance for Local Science and Technology Development; Ministry of Agriculture Central China Potato Observation and Experiment Station, Fundamental Research Funds for the Central Universities (Grant no. 2017RC001 to B.L.)

\section{Availability of data and materials}

The mass spectrometry proteomics data have been deposited to the ProteomeXchange Consortium (http://proteomecentral.proteomexchange. org) via the iProX partner repository with the dataset identifier PXD014647.

Ethics approval and consent to participate

Not applicable.

\section{Consent for publication}

'Not applicable'.

\section{Competing interests}

The authors declare that the research was conducted in the absence of any commercial or financial relationships that could be construed as a potential conflict of interest.

\section{Author details}

'State Key Laboratory of Agricultural Microbiology and Hubei Key Laboratory of Plant Pathology, College of Plant Science and Technology, Huazhong Agricultural University, Wuhan 430070, Hubei, China. ${ }^{2}$ Southern Potato Research Center of China, Enshi 445000, Hubei, China. ${ }^{3}$ Enshi Tujia and Miao Autonomous Prefecture Academy of Agricultural Sciences, Enshi 445000, Hubei, China.

Received: 2 September 2020 Accepted: 26 November 2020

Published online: 09 December 2020

\section{References}

1. Fry WE, Birch PR, Judelson HS, Grünwald NJ, Danies G, Everts $K L$, Gevens AJ, Gugino BK, Johnson DA, Johnson SB, McGrath MT, Myers KL, Ristaino JB, Roberts PD, Secor G, Smart CD. Five reasons to consider Phytophthora infestans a reemerging pathogen. Phytopathology. 2015;105(7):966-81. https://doi.org/10.1094/PHYTO-01-15-0005-FI.

2. Fry W. Phytophthora infestans: the plant (and R gene) destroyer. Mol Plant Pathol. 2008:9(3):385-402. https://doi.org/10.1111/j.1364-3703.2007.00465.x.

3. Song J, Bradeen JM, Naess KS, Raasch JA, Wielgus SM, Haberlach GT, Liu J, et al. Gene RB cloned from Solanum bulbocastanum confers broad spectrum resistance to potato late blight. Proc Natl Acad Sci U S A. 2003; 100(16):9128-33. https://doi.org/10.1073/pnas.1533501100.

4. Haas BJ, Kamoun S, Zody MC, Jiang RHY, Handsaker RE, Cano LM, Grabherr $M$, et al. Genome sequence and analysis of the Irish potato famine pathogen Phytophthora infestans. Nature. 2009;461(7262):393-8. https://doi. org/10.1038/nature08358.

5. Ali A, Alexandersson E, Sandin M, Resjö S, Lenman M, Hedley P, Levander F Andreasson E. Quantitative proteomics and transcriptomics of potato in response to Phytophthora infestans in compatible and incompatible interactions. BMC Genomics. 2014;15(1):1-18.

6. Becktell MC, Daughtrey ML, Fry WE. Temperature and leaf wetness requirements for pathogen establishment, incubation period, and sporulation of Phytophthora infestans on Petunia $\times$ hybrida. Plant Dis. 2005; 89(9):975-9.

7. Park TH, Vleeshouwers VGAA, Huigen DJ, et al. Characterization and high-resolution mapping of a late blight resistance locus similar to R2 in potato. Theor Appl Genet. 2005;111(3):591-7. https://doi.org/10.1007/ s00122-005-2050-4

8. Mauch F, Hadwiger LA, Boller T. Ethylene: symptom, not signal for the induction of Chitinase and $\beta-1,3-$ Glucanase in pea pods by pathogens and elicitors. Plant Physiol. 1984;76(3):607-11. https://doi.org/10.1104/pp.76.3.607.

9. Didier A, Pilet F, Montarry J, Hafidi M, Corbière R, Achbani EH, Pellé R, Ellissèche D. Adaptation of Phytophthora infestans to partial resistance in potato: evidence from French and Moroccan populations. Phytopathology. 2007;97(3):338-43. https://doi.org/10.1094/PHYTO-97-3-0338.

10. Chaparro-Garcia A, Wilkinson RC, Gimenez-lbanez S, Findlay K, Coffey MD, Zipfel C, et al. The receptor-like kinase SERK3/BAK1 is required for basal resistance against the late blight pathogen Phytophthora infestans in Nicotiana benthamiana. PLoS One. 2011;6(1):e16608. https://doi.org/10.1371/ journal.pone.0016608.

11. Bos JIB, Chaparro-Garcia A, Quesada-Ocampo LM, Gardener BBM, Kamoun K Distinct amino acids of the Phytophthora infestans effector AVR3a condition activation of R3a hypersensitivity and suppression of cell death. Mol PlantMicrobe Interact. 2009;22(3):269-81. https://doi.org/10.1094/MPMI-22-3-0269. 
12. Gyetvai G, Sønderkær M, Göbel U, Basekow R, Ballvora A, Imhoff M, et al. The Transcriptome of compatible and incompatible interactions of potato (Solanum tuberosum) with Phytophthora infestans revealed by DeepSAGE analysis. PLoS One. 2012;7(2):e31526. https://doi.org/10.1371/ journal.pone.0031526.

13. Lindqvist-Kreuze H, Carbajulca D, Gonzalez-Escobedo G, Pérez W, Bonierbale M. Comparison of transcript profiles in late blight-challenged Solanum cajamarquense and B3C1 potato clones. Mol Plant Pathol. 2010;11(4):51330. https://doi.org/10.1111/j.1364-3703.2010.00622.x.

14. Coll NS, Epple P, Dangl JL. Programmed cell death in the plant immune system. Cell Death Differ. 2011;18(8):1247-56. https://doi.org/10.1038/cdd.2011.37.

15. Berre $J Y L$, Engler $G$, Panabières $F$. Exploration of the late stages of the tomato-Phytophthora parasitica interactions through histological analysis and generation of expressed sequence tags. New Phytol. 2008;177(2):48092. https://doi.org/10.1111/j.1469-8137.2007.02269.x.

16. Burra DD, Berkowitz $\mathrm{O}$, Hedley $\mathrm{PE}$, et al. Phosphite-induced changes of the transcriptome and secretome in Solanum tuberosum leading to resistance against Phytophthora infestans. BMC Plant Biol. 2014;14(1):1-17. https://doi. org/10.1186/s12870-014-0254-y.

17. Fritzemeier $\mathrm{KH}$, Cretin C, Kombrink E, et al. Transient induction of phenylalanine Ammonia-Lyase and 4-Coumarate: CoA ligase mRNAs in potato leaves infected with virulent or Avirulent races of Phytophthora infestans. Plant Physiol. 1987;85(1):34-41. https://doi.org/10.1104/pp.85.1.34.

18. Schütze K, Harter K, Chaban C. Post-translational regulation of plant bZIP factors. Trends Plant Sci. 2008;13(5):247-55. https://doi.org/10.1016/j.tplants.2008.03.002.

19. Larsen MK, Jørgensen MM, Bennike TB, Stensballe A. Time-course investigation of Phytophthora infestans infection of potato leaf from three cultivars by quantitative proteomics. Data Brief. 2015;6:238-48. https://doi. org/10.1016/j.dib.2015.11.069.

20. Werner T, Sweetman G, Savitski MF, Mathieson T, Bantscheff M, Savitski MM Ion coalescence of neutron encoded TMT 10-Plex reporter ions. Anal Chem. 2014;86(7):3594-601. https://doi.org/10.1021/ac500140s.

21. Resjö S, Brus M, Ali A, Harold JG, Meijer HJG, Sandin M, Govers F, Levander F, Grenville-Briggs $L$, Andreasson E. Proteomic analysis of Phytophthora infestans reveals the importance of Cell Wall proteins in pathogenicity. Mol Cell Proteomics. 2017;16(11):1958-71. https://doi.org/10.1074/mcp.M116.065656.

22. Li X, Xu J, Duan S, Bian C, Hu J, Shen H, Li G, Jin L. Pedigree-based deciphering of genome-wide conserved patterns in an elite potato parental line. Front Plant Sci. 2018;9:690. https://doi.org/10.3389/fpls.2018.00690.

23. Duan $Y$, Liu J, Xu J, et al. DNA fingerprinting and genetic diversity analysis with simple sequence repeat markers of 217 potato cultivars (Solanum tuberosum L.) in China. Am J Potato Res. 2019;96:21-32. https://doi.org/10. 1007/s12230-018-9685-6.

24. Xiao C, Gao J, Zhang Y, Wang Z, Zhang D, Chen Q, Ye X, Xu Y, Yang G, Yan L, Cheng Q, Chen J, Shen Y. Quantitative Proteomics of Potato Leaves Infected with Phytophthora infestans Provides Insights into Coordinated and Altered Protein Expression during Early and Late Disease Stages. Int J Mol Sci. 2019;20:136. https://doi.org/10.3390/ijms20010136.

25. Bachmann A, Hause B, Maucher H, Garbe E, Vörös K, Weichert H, Wasternack C, Feussner I. Jasmonate-Induced Lipid Peroxidation in Barley Leaves Initiated by Distinct 13-LOX Forms of Chloroplasts. Biol Chem. 2002;383(10): 1645-57. https://doi.org/10.1515/BC.2002.185.

26. May MJ, Hammond-Kosack KE, Jones JDG. Involvement of reactive oxygen species, glutathione metabolism, and lipid peroxidation in the Cf-genedependent defense response of tomato cotyledons induced by racespecific elicitors of Cladosporium fulvum. Plant Physiol. 1996;110(4):1367-79. https://doi.org/10.1104/pp.110.4.1367.

27. Ali A, Moushib LI, Lenman M, Levander F, Olsson K, Carlson-Nilson U, Zoteyeva N, Liljeroth E, Andreasson E. Paranoid potato: phytophthoraresistant genotype shows constitutively activated defense. Plant Signal Behav. 2012;7(3):400-8.

28. Huh GH, Lee SJ, Bae YS, Liu JR, Kwak SS. Molecular cloning and characterization of cDNAs for anionic and neutral peroxidases from suspensioncultured-cells of sweet potato and their differential expression in response to stress. Mol Gen Genet. 1992;255(4):382-91. https://doi.org/10.1007/s004380050510.

29. Wu T, Tian Z, Liu J, Xie C. A novel leucine-rich repeat receptor-like kinase gene in potato, StLRPK1, is involved in response to diverse stresses. Mol Biol Rep. 2009;36(8):2365-74. https://doi.org/10.1007/s11033-009-9459-9.

30. Gao L, Bradeen JM. Contrasting potato foliage and tuber defense mechanisms against the late blight pathogen Phytophthora infestans. PLoS One. 2016;11(7):e0159969. https://doi.org/10.1371/journal.pone.0159969.
31. Dóczi R, Kondrák M, Kovács G, Beczner F, Bánfalvi Z. Conservation of the drought-inducible DS2 genes and divergences from their ASR paralogues in solanaceous species. Plant Physiol Biochem. 2005;43(3):269-76. https://doi. org/10.1016/j.plaphy.2005.02.002.

32. Kim JY, Park SC, Hwang I, et al. Protease inhibitors from plants with antimicrobial activity. Int J Mol Sci. 2009;10(6):2860-72. https://doi.org/10. 1016/j.bbrc.2005.03.057.

33. Vijayan P, Shockey J, Lévesque CA, Cook RJ, Browse J. A role for jasmonate in pathogen defense of Arabidopsis. Proceed Nat Acad Sci U S A. 1998; 95(12):7209-14. https://doi.org/10.1073/pnas.95.12.7209.

34. Riemann M, Haga K, Shimizu T, Okada K, Ando S, Mochizuki S, Nishizawa Y, Yamanouchi U, Nick P, Yano M, Minami E, Takano M, Yamane H, lino M. Identification of rice Allene oxide Cyclase mutants and the function of jasmonate for defence against Magnaporthe oryzae. Plant J. 2013;74(2):22638. https://doi.org/10.1111/tpj.12115.

35. Mérillon JM, Ramawat KG. Plant Defence: biological control v-vi. Progress in biological control book series (PIBC, volume 12); 2012. https://doi.org/10. 1007/978-94-007-1933-0.

36. Nagaraj S, Senthil-Kumar M, Ramu VS, Wang K, Mysore KS. Plant ribosomal proteins, RPL12 and RPL19, Play a Role in Nonhost Disease Resistance against Bacterial Pathogens. Front Plant Sci. 2016;6:1192. https://doi.org/10. 3389/fpls.2015.01192.

37. Ros R, Muñoz-Bertomeu J, Krueger S. Serine in plants: biosynthesis, metabolism, and functions. Trends Plant Sci. 2014;19(9):564-9. https://doi. org/10.1016/j.tplants.2014.06.003.

38. Ann A, Schloss JV. Oxalyl hydroxamates as reaction-intermediate analogs for ketol-acid reductoisomerase. Biochemistry. 1990;29(11):2824-30.

39. Muñoz-Bertomeu J, Anoman A, Flores-Tornero M, Toujani W, Rosa-Téllez S, Fernie AR, Roje S, Segura J, Ros R. The essential role of the phosphorylated pathway of serine biosynthesis in Arabidopsis. Plant Signal Behav. 2013; 8(11):e27104. https://doi.org/10.4161/psb.27104.

40. Wang T, Sui Z, Liu X, Li Y, Li H, Xing J, Song F, Zhang Y, Sun Q, Ni Z. Ectopic expression of a maize hybrid up-regulated gene, ErbB-3 binding protein 1 (ZmEBP1), increases organ size by promoting cell proliferation in Arabidopsis. Plant Sci. 2016;243:23-34. https://doi.org/10.1016/j. plantsci.2015.11.002

41. Mehrotra R, Bhalothia P, Bansal P, Basantani MK, Bharti V, Mehrotra S. Abscisic acid and abiotic stress tolerance - Different tiers of regulation. J Plant Physiol. 2014;171(7):486-96. https://doi.org/10.1016/j.jplph.2013.12.007.

42. Bray EA. Plant responses to water deficit. Trends Plant Sci. 1997;2(2):48-54. https://doi.org/10.1016/S1360-1385(97)82562-9.

43. Vleeshouwers V, van Dooijeweert W, Govers F, et al. The hypersensitive response is associated with host and nonhost resistance to Phytophthora infestans. Planta. 2000;210:853-64. https://doi.org/10.1007/s004250050690.

44. Kaschani F, Shabab M, Bozkurt T, Shindo T, Schornack S, Gu C, llyas M, Win J, Kamoun S, van der Hoorn RA. An effector-targeted protease contributes to defense against Phytophthora infestans and is under diversifying selection in natural hosts. Plant Physiol. 2010;154(4):1794-804. https://doi. org/10.1104/pp.110.158030.

45. Dunaevsky YE, Popova W, Semenova TA, Beliakova GA, Belozersky MA. Fungal inhibitors of proteolytic enzymes: classification, properties, possible biological roles, and perspectives for practical use. Biochimie. 2013;101(1): 10-20. https://doi.org/10.1016/j.biochi.2013.12.007.

46. Santos CVD, Pascal RP. Plant thioredoxins are key actors in the oxidative stress response. Trends Plant Sci. 2006;11(7):329-34 doi: 10.1016/j.tplants. 2006; 05.005 .

47. Kaushik D, Roychoudhury A. Reactive oxygen species (ROS) and response of antioxidants as ROS-scavengers during environmental stress in plants. Front Environ Sci. 2014:1-13. https://doi.org/10.3389/fenvs.2014.00053.

48. Szamosi I, Shaner DL, Bijay KS. Identification and characterization of a Biodegradative form of threonine Dehydratase in senescing tomato (Lycopersicon esculentum) leaf. Plant Physiol. 1993;101(3):999-1004. https:// doi.org/10.1104/pp.101.3.999.

49. Zaffagnini M, Fermani S, Costa A, Lemaire SD, Trost P. Plant cytoplasmic GAPDH: redox post-translational modifications and moonlighting properties. Front Plant Sci. 2013:4:450. https://doi.org/10.3389/fpls.2013.00450.

50. Veramendi J, Fernie AR, Leisse A, Willmitzer L, Trethewey RN. Potato hexokinase 2 complements transgenic Arabidopsis plants deficient in hexokinase 1 but does not play a key role in tuber carbohydrate metabolism. Plant Mol Biol. 2002;49(5):491-501. https://doi.org/10.1023/A: 1015528014562 
51. Lurie S, Zhou HW, Lers A, Sonego L, Alexandrov S, Shomer I. Study of pectin esterase and changes in pectin methylation during normal and abnormal peach ripening. Physiol Plant. 2003;119(2):287-94. https://doi.org/10.1034/j. 1399-3054.2003.00178.x.

52. Ellens KW, Richardson LGL, Frelin O, Collins J, Ribeiro CL, Hsieh YF, Mullen RT, Hanson AD. Evidence that glutamine transaminase and omega-amidase potentially act in tandem to close the methionine salvage cycle in bacteria and plants. Phytochemistry. 2015;113:160-9. https://doi.org/10.1016/j. phytochem.2014.04.012.

53. Sauter M, Moffatt B, Saechao MC, Hell R, Wirtz M. Methionine salvage and Sadenosylmethionine: essential links between sulfur, ethylene and polyamine biosynthesis. Biochem J. 2013;451(2):145-54. https://doi.org/10.1042/ BJ20121744.

54. Kim SH, Kim SH, Palaniyandi SA, Yang SH, Suh JW. Expression of potato Sadenosyl-I-methionine synthase (SbSAMS) gene altered developmental characteristics and stress responses in transgenic Arabidopsis plants. Plant Physiol Biochem. 2015;87:84-91. https://doi.org/10.1016/j.plaphy.2014.12.020.

55. Abrahamian M, Ah-Fong AM, Davis C, Andreeva K, Judelson HS. Gene expression and silencing studies in Phytophthora infestans reveal infectionspecific nutrient transporters and a role for the nitrate Reductase pathway in plant pathogenesis. PLoS Pathog. 2016;12(12):e1006097.

56. Lee IR, Carl AM, Fraser JA. Nitrogen regulation of virulence in clinically prevalent fungal pathogens. FEMS Microbiol Lett. 2013;345(2):77-84. https:// doi.org/10.1111/1574-6968.12181

57. Takemoto D, Furuse K, Doke N, Kawakita K. Identification of Chitinase and Osmotin-like protein as actin-binding proteins in suspension-cultured potato cells. Plant Cell Physiol. 1997;38(4):441-8. https://doi.org/10.1093/ oxfordjournals.pcp.a029187.

58. Spaink HP. Specific recognition of bacteria by plant LysM domain receptor kinases. Trends Microbiol. 2004;12(5):201-4. https://doi.org/10.1016/j.tim. 2004.03.001.

59. Katou S, Yamamoto A, Yoshioka H, et al. Functional analysis of potato mitogen-activated protein kinase Katoa, StMEK1. J Gen Plant Pathology. 2003:69:161-8. https://doi.org/10.1007/s10327-002-0030-y.

60. Unal ZZ, Nandi AK. Arabidopsis thaliana GLUTATHIONE-S-TRANSFERASE THETA 2 interacts with RSI1/FLD to activate systemic acquired resistance. Mol Plant Pathol. 2018;19(2):464-75.

61. Min K, Ha SC, Hasegawa PM, Bressan RA, Yun D, Kyeong KK. Crystal structure of osmotin, a plant antifungal protein. Proteins Structure Function Bioinformatics. 2004;173:170-3.

62. Niki T, Mitsuhara I, Seo S, Ohtsubo N, Ohashi Y. Antagonistic effect of salicylic acid and Jasmonic acid on the expression of pathogenesis-related (PR) protein genes in wounded mature tobacco leaves. Plant Cell Physiol. 1998;39(5):500-7. https://doi.org/10.1093/oxfordjournals.pcp.a029397.

63. Stotz HU, Thomson JG, Wang Y. Plant defensins: Defense, development and application. Plant Signal Behav. 2009;4(11):1010-2. https://doi.org/10.4161/ psb.4.11.9755.

64. Unal CM, Steinert M. Microbial Peptidyl-Prolyl cis/trans Isomerases (PPlases): virulence factors and potential alternative drug targets. Microbiol Mol Biol Rev. 2014;78(3):544-71. https://doi.org/10.1128/mmbr.00015-14.

65. Chen L, Shimamoto K. Emerging roles of molecular chaperones in plant innate immunity. J Gen Plant Pathol. 2011;2011(77):1-9. https://doi.org/10. 1007/s10327-010-0286-6.

66. País SM, Téllez-Iñón MT, Capiati DA. Serine/threonine protein phosphatases type $2 \mathrm{~A}$ and their roles in stress signalin. Plant Signal Behav. 2009;4(11): 1013-5. https://doi.org/10.4161/psb.4.11.9783.

67. Anwar A, She M, Wang K, Riaz B, Ye X. Biological Roles of Ornithine Aminotransferase (OAT) in Plant Stress Tolerance: Present Progress and Future Perspectives. Int J Mol Sci. 2018. https://doi.org/10.3390/ ijms19113681.

68. Zhang C, Wang D, Yang C, Kong N, Shi Z, Zhao P, et al. Genome-wide identification of the potato WRKY transcription factor family. PLoS One. 2017;12(7):e0181573. https://doi.org/10.1371/journal.pone.0181573.

69. Aldon D, Mbengue M, Mazars C, Galaud JP. Calcium Signalling in plant biotic interactions. Int J Mol Sci. 2018;19(3):665. https://doi.org/10.3390/ijms19030665.

70. Chandra S. Natural plant genetic engineer agrobacterium rhizogenes: role of T-DNA in plant secondary metabolism. Biotechnol Lett. 2012;34:407-15. https://doi.org/10.1007/s10529-011-0785-3.

71. Ludger J, Römer W. Shiga toxins — from cell biology to biomedical applications. Nat Rev Microbiol. 2010;8(2):105-16. https://doi.org/10.1038/ nrmicro2279.
72. Mandon EC, Trueman SF, Gilmore R. Protein translocation across the rough endoplasmic reticulum. Cold Spring Harb Perspect Biol. 2013. https://doi. org/10.1101/cshperspect.a013342.

73. Liu Y, Hüttenhain R, Collins B, Aebersold R. Mass spectrometric protein maps for biomarker discovery and clinical research. Expert Rev Mol Diagn. 2013;13(8):811-25. https://doi.org/10.1586/14737159.2013.845089.

74. Hung CW, Tholey A. Tandem mass tag protein labeling for top-down identification and quantification. Anal Chem. 2012;84(1):161-70. https://doi. org/10.1021/ac202243r.

75. Ma J, Chen T, Wu S, Yang C, Bai M, Shu K, Li K, et al. iProX: an integrated proteome resource. Nucleic Acids Res. 2019;47(D1):D1211-7. https://doi.org/ 10.1093/nar/gky869.

76. Ana C, and Götz S. Blast2GO: A Comprehensive Suite for Functional Analysis in Plant Genomics" International Journal of Plant Genomics. https://doi.org/ 10.1155/2008/619832

77. Kanehisa M, Furumichi M, Tanabe M, Sato Y, Morishima K. KEGG: new perspectives on genomes, pathways, diseases and drugs. Nucleic Acid Res. 45(D1):D353-61. https://doi.org/10.1093/nar/gkw1092.

78. Ogata H, Goto S, Sato K, Fujibuchi W, Bono H, Kanehisa M. KEGG: Kyoto encyclopedia of genes and genomes. Nucleic Acids Res. 1999;27(1):29-34. https://doi.org/10.1093/nar/27.1.29.

79. Aldridge GM, Podrebarac DM, Greenough WT, Weiler IJ. The use of total protein stains as loading controls: an alternative to high-abundance singleprotein controls in semi-quantitative immunoblotting. J Neurosci Methods. 2008;172(2):250-4.

80. Wong C, Sridhara S, Bardwell JCA, Jakob U. Heating greatly speeds Coomassie blue staining and Destaining. BioTechniques. 2000;28(3):426-32. https://doi.org/10.2144/00283bm07.

81. Livak KJ, Schmittgen TD. Analysis of relative gene expression data using real-time quantitative PCR and the $2-\Delta \Delta C T$ method. Methods. 2011;25(4): 402-8. https://doi.org/10.1006/meth.2001.1262.

\section{Publisher's Note}

Springer Nature remains neutral with regard to jurisdictional claims in published maps and institutional affiliations.
Ready to submit your research? Choose BMC and benefit from:

- fast, convenient online submission

- thorough peer review by experienced researchers in your field

- rapid publication on acceptance

- support for research data, including large and complex data types

- gold Open Access which fosters wider collaboration and increased citations

- maximum visibility for your research: over $100 \mathrm{M}$ website views per year

At BMC, research is always in progress.

Learn more biomedcentral.com/submissions 